\title{
Article \\ Structural Aspects and Characterization of Structure in the Processing of Titanium Grade4 Different Chips
}

\author{
Krzysztof Topolski *D, Jakub Jaroszewicz and Halina Garbacz \\ Faculty of Materials Science and Engineering, Warsaw University of Technology, Wołoska 141, \\ 02-507 Warsaw, Poland; jakub.jaroszewicz@pw.edu.pl (J.J.); halina.garbacz@pw.edu.pl (H.G.) \\ * Correspondence: kt.topolski@gmail.com; Tel.: +48-22-2348740
}

check for updates

Citation: Topolski, K.; Jaroszewicz, J.; Garbacz, H. Structural Aspects and Characterization of Structure in the Processing of Titanium Grade4 Different Chips. Metals 2021, 11, 101. https://doi.org/10.3390/met11010101

Received: 7 December 2020 Accepted: 30 December 2020 Published: 6 January 2021

Publisher's Note: MDPI stays neutral with regard to jurisdictional clai$\mathrm{ms}$ in published maps and institutional affiliations.

Copyright: (C) 2021 by the authors. Licensee MDPI, Basel, Switzerland. This article is an open access article distributed under the terms and conditions of the Creative Commons Attribution (CC BY) license (https:// creativecommons.org/licenses/by/ $4.0 /)$.

\begin{abstract}
This study presents the structural aspects of the solid-state processing of various titanium chips. The structural characterization of: (1) commercial pure Ti in the as-received state, (2) manufactured chips, and (3) products of the chip processing are presented. Pure single-phase titanium Grade4 (Ti Gr4) was processed which, among all grades of pure titanium, is characterized by the lowest possible purity and the highest possible strength at the same time. Four geometries of chips were processed, i.e., chips after turning (thin and coarse), and chips after milling (thin and coarse). An unconventional plastic working method was applied to transform a dispersed form (chips) into solid, bulk metal in the form of rods without re-melting. The rods with a diameter of $\varnothing 8 \mathrm{~mm}$ and a length of about $500 \mathrm{~mm}$ were manufactured. Based on computer tomography and Archimedes measurements, it was found that the manufactured rods were consolidated and near fully dense. In turn, microscopy investigations proved that conventional, polycrystalline, grained structures were obtained. Only an insignificantly small number of internal defects were revealed, meaning that the obtained rods exhibited a proper structure typical for commercial titanium. Obtained materials, except of small surface inclusions, were fee of impurities. Whereas the results of the compression tests proved that the manufactured rods are characterized by new interatomic bonds, cohesion and plasticity analogous to those of titanium in the as-received state.
\end{abstract}

Keywords: titanium; chips; structural properties; structural characterization; recycling

\section{Introduction}

For many years, the recycling of metals has been an important and developing field of industry. One area of this industry is the processing of chips and its transformation to useful semi-products. A basic technique of metal chips recycling is remelting. However, remelting is characterized by relatively high energy consumption, emissions of harmful gases, and solid waste. In addition, in the case of titanium and its alloys, protection against atmospheric air is necessary.

An alternative technique for chips recycling is processing without remelting, i.e., solid state processing. This is carried out using plastic working technology at an elevated temperature. For this purpose, (1) conventional methods of plastic working (direct extrusion [1-3], rolling [1,4]) as well as relatively new, (2) unconventional methods (Severe Plastic Deformation (SPD) [5-9], the KOBO method [10,11], friction stir extrusion [12] or friction back extrusion [13]) are used. In recent years, in this field, a significant increase in the number of publications on the subject has been observed.

In the context of solid state chips treatment, the most commonly processed metals are aluminum and its alloys [1,2,5,11,13-15], followed by magnesium and its alloys [3,5,12,16,17], whereas there is relatively little data in the literature on the processing of chips of pure titanium and its alloys [4,7-10,18].

In the context of chip processing-recycling, the structure of the material obtained is an important issue. The final quality and properties of the manufactured recycled products 
depend on: the amount and type of internal defects, impurities, chip bonding, grain shape, and grain size. Especially in the case of plastic working obtaining a proper structure (transformed from a dispersed form into a bulk and solid state without remelting) is a challenge. Hence, in order to consolidate chips into a new solid structure, the following conditions must be fulfilled: (1) sufficiently high stress, (2) sufficiently high temperature, (3) sufficiently high plastic deformation, and no external contamination $[1,2,14]$.

Chips are dispersed macroscopic forms that have their own microstructure. After initial consolidation, the chips form a briquette, which is a consolidated macro-element having their own macrostructure consisting of chips. It should be noted that these chips have still their own microstructure. Therefore, in the context of chip processing, the material structure during, and after recycling, can be considered as both macrostructure and microstructure. The properties of the material structure after processing are important, because they determine whether the chip recycling process has been carried out correctly or incorrectly. A proper and defect-free structure ensures that the product possesses the quality and properties needed for it to be useful.

In the area of the processing of chips of titanium and its alloys, some studies in the literature regarding structural investigations are worthy of mention. For example, in the work [4] chips of pure titanium VT1-0 grade were processed by hot rolling, and this way strips were produced. That work presents the metallographic microstructures immediately after hot rolling, as well after annealing and recrystallization. In turn, in work [7] the ECAP method with back pressure was applied to recycle pure titanium Grade2 chips after milling. As a result, dense and consolidated products in the form of rods were manufactured. In order to characterize the obtained microstructures, high resolution electron backscatter diffraction (EBSD), transmission electron microscopy (TEM) and light microscopy were employed. Whereas in work [8], various types of Ti6Al4V chips were recycled using ECAP with back pressure and hot forging to produce the desired final microstructure. In that work, scanning electron microscopy (SEM) was used to observe the microstructures and chip boundaries. Another example of Ti6Al4V chips processed by ECAP with back pressure was presented in work [9]. In that study, structural effects, including chips interlocking, were analyzed using SEM and light microscopy, while transmission electron microscopy (TEM) was used to analyze the banded structure.

The novelty of our work is: (1) the material processed (tough pure mono-phase $\alpha$ titanium Grade4 with the highest possible hardness and strength), (2) the geometry of the materials (various shapes and thicknesses of chips), and (3) the unconventional plastic working technique, which makes it possible to process chips in the solid state, without remelting (direct extrusion with cyclic die rotation realized in two directions). The processing of titanium chips like these without remelting has not been the subject of any previous research, particularly in the context of structural analyses using such techniques of investigations.

The aim of this study is to present the structural aspects and structural transformation resulting from the solid state processing of various titanium chips. Four types of titanium chips were processed into four individual rods. These materials were characterized by means of a complex structural investigation. The effect of chip type on the results obtained is presented. Moreover, the relationship between the processing and the structures thus obtained is analyzed.

\section{Materials Investigated}

In this work, the material processed and investigated was pure mono-phase $\alpha$ titanium Grade4 (Ti Gr4) representing (among all grades of pure titanium) the lowest possible purity as well as the highest possible yield stress, tensile strength and hardness. Its chemical composition is given in Table 1. Generally, Ti Gr4 exhibits significantly higher strength and hardness than other grades of Ti and is more contaminated and less ductile. Therefore Ti Gr4 was hard to deform and more difficult to process. For example, the hardness of this 
material in the as-received state was 190 HV10, whereas the yield stresses (evaluated by compression tests) was $492 \mathrm{MPa}$.

In the as-received state, this investigated material was in the form of rod. The rod was subjected to machining into specific chips in order to obtain various and required types of chips (variants V1-V4). Ti Gr4 rod was subjected to turning (variants V1, V2) and milling (variants V3, V4) for two thickness of chips each time. The machining processes were carried out under conditions without emulsion cooling. This approach reduced the contamination of the chips. After the machining, the chips thus obtained were cleaned using acetone and an ultrasonic washing machine.

Next step of the processing was an initial consolidation of the chips into briquettes, heating, and finally, the extrusion of the briquettes into the final products in the form of rods.

Table 1. Chemical composition of investigated titanium Grade4.

\begin{tabular}{ccccccccc}
\hline Element & $\mathbf{F e}$ & $\mathbf{O}$ & $\mathbf{N}$ & $\mathbf{H}$ & $\mathbf{C}$ & $\mathbf{A l}$ & $\mathbf{V}$ & $\mathbf{T i}$ \\
\hline [\%] weight & 0.314 & 0.26 & 0.012 & 0.001 & 0.02 & - & - & Base \\
\hline
\end{tabular}

\section{Investigation Methods}

The structural characterization of the manufactured materials was conducted using: (1) computer tomography, (2) density measurements, (3) fluorescence spectrometry, (4) energy dispersive spectroscopy, (5) light microscopy, and (6) scanning electron microscopy.

To investigate and illustrate the transformation effect, $\mathrm{X}$-ray computer tomography was used (Xradia Micro XCT 400 tomograph). Structural research using this method was carried out at a resolution of $25 \mu \mathrm{m}$ (the "detection threshold"), meaning that any structural elements (e.g., pores) smaller than $25 \mu \mathrm{m}$ were not detected. The samples intended for computer tomography investigation were $8 \mathrm{~mm}$ in diameter and $50 \mathrm{~mm}$ long, thus they were volumetric and bulk materials. They were cut out from the middle of the rods and then cleaned using acetone and an ultrasonic washing machine.

The density measurements were performed using the Archimedes method and an analytical balance with an accuracy of $0.01 \mathrm{~g} / \mathrm{cm}^{3}$. Exactly the same samples as for the computer tomography were used for the density measurements. The tests were carried out on the samples in as-received state (reference) and on all variants after processing. Three measurements were made for each sample.

In order to evaluate the potential contamination of the manufactured rods, chemical composition measurements using X-ray fluorescence spectrometry were realized. An Olympus DELTA XRF spectrometer was used. This device makes it possible to measure a surface in area of diameter of $1.5 \mathrm{~mm}$ and a depth of up to $100 \mu \mathrm{m}$. The samples were tested: (1) on the external cylindrical surface, (2) in transverse section, and (3) in longitudinal section. For each sample and area, two measurements were taken at random locations. The tests were carried out on the samples in as-received state (reference) and for all variants after processing.

To obtain additional information about the chemical composition and chemical purity of the manufactured rods, the chemical microanalysis using scanning electron microscopy with energy dispersive spectroscopy attachment (SEM-EDS) was also used. Samples from each variant (V1-V4) were tested. Each variant was examined using one sample presenting transverse section and one sample presenting longitudinal sections. Moreover, two analyzes were performed for each sample: (1) on the circuit of the sample-rod, (2) in the area of the axis-center of the sample-rod. This gave sixteen measurements in total. The samples were subjected to elemental qualitative and quantitative analysis by taking a spectrum from their surface. Square areas with dimensions of $1 \mathrm{~mm} \times 1 \mathrm{~mm}$ were analyzed.

In order to reveal the microstructures of the processed materials, the samples were ground, polished and etched. In this way special metallographic samples were prepared. On the transverse section, for each variant the entire area of the sample was etched and 
analyzed, i.e., the area of a circle with a diameter of $8 \mathrm{~mm}$. Similarly, in the longitudinal section, the entire area of the sample section was etched and analyzed. In the longitudinal section, the tested surface was rectangular, with sides of $8 \mathrm{~mm}$ (height) $\times 10 \mathrm{~mm}$ (length). The revealed microstructures were analyzed using light microscopy. For the purpose of estimating grain size and grain shape, image analysis software was used [19]. The grains were characterized based on the following stereological parameters: (1) average grain size $\mathrm{E}\left(\mathrm{d}_{2}\right)$ (i.e., the average value $(\mathrm{E})$ of the average equivalent grain diameters $\left.\left(\mathrm{d}_{2}\right)\right),(2)$ $\mathrm{SD}$ —standard deviation, (3) $\mathrm{CV}$ - coefficient of variation (where $\mathrm{CV}=\mathrm{SD}$ / average grain size), (4) " $\alpha$ " shape factor (defined as: $\alpha=d_{\max } / d_{2}$, where $d_{\max }$ is the maximum chord of a grain), and (5) " $\beta$ " shape factors (defined as: $\beta=p /\left(\pi^{*} d_{2}\right)$, where " $p$ " is the perimeter of a grain). It should be clarified that " $\alpha$ " shape factors determine the deviation of the shape of a grain from that of a circle, and characterize the elongation of the grain, while " $\beta$ " shape factors determine the degree of development of the grain boundary surface. For each case, approximately one hundred grains were used for the stereological analysis.

Some of the structural examinations were also performed in a scanning electron microscope (SEM, Hitachi S3500) using the secondary electron (SE) mode. Observation was performed on the transverse and longitudinal sections of the samples.

The compression tests were conducted at room temperature using a universal vertical MTS 858 hydraulic testing machine. The samples had the standard cylindrical shape and were $7 \mathrm{~mm}$ in diameter and $10.5 \mathrm{~mm}$ high (height to diameter ratio equal 1.5). Two tests were conducted for each state of material.

\section{Results and Discussion}

The processing procedure consisted of the following stages: (1) characterization of titanium in the as received state, (2) the machining of the $\mathrm{Ti}$ in the as-received state into the specific chips required, (3) the preliminary consolidation of the chips into the form of "briquettes", (4) the heating of the briquettes before extrusion, and (5) extrusion of the briquettes into the form of solid rods using the KOBO method.

\subsection{Titanium in the As-Received State}

Light microscopy observations of the etched samples revealed that the microstructures of Ti Gr4 in the as-received state were the same in the transverse section (Figure 1a) and in the longitudinal section (Figure 1b). In both these cases, the microstructure was characterized by equiaxed grains whose size ranged from 10-50 $\mu \mathrm{m}$. For the transverse section, the average grain size of the initial Ti Gr4 was $32 \mu \mathrm{m}$ (with SD =9.71, CV =0.30), while for the longitudinal section $28 \mu \mathrm{m}$ (with $\mathrm{SD}=8.34, \mathrm{CV}=0.30$; also see Table 8).
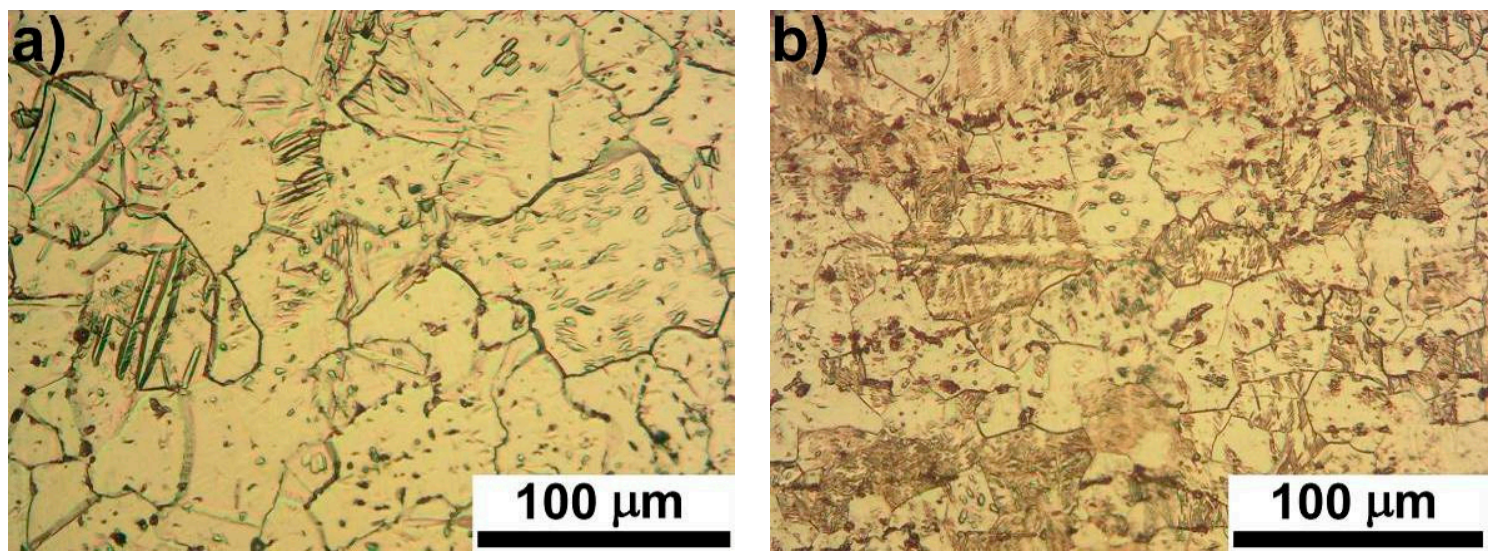

Figure 1. Samples of microstructures revealed by etching, Ti Gr4 as-received state, light microscopy: (a) transverse section, (b) longitudinal section. 
The average density of the Ti Gr4 in the as-received state was $4.51\left[\mathrm{~g} / \mathrm{cm}^{3}\right]$. This value, measured by the Archimedes method, was consistent with the theoretical value of titanium $\left(4.51\left[\mathrm{~g} / \mathrm{cm}^{3}\right]\right)$. As mentioned previously, among others titanium grades, Ti Gr4 is tough grade. For example, the hardness of the processed Ti in the as-received state was 190 HV10, whereas the yield stresses (evaluated by compression tests) was $492 \mathrm{MPa}$.

\subsection{Chips Manufactured by Machining}

In this step of processing, Ti Gr4 rod in the as-received state was subjected to turning and milling without any cooling with the aim to produce the various, specific chips. The chips were prepared by (1) turning and (2) milling. Beside, for each type of these chip, two thicknesses were prepared: (1) thin $(\sim 0.1 \mathrm{~mm})$ and (2) coarse $(\sim 0.3-0.4 \mathrm{~mm})$, thus making four variants of the experiments. A detailed description of these variants is provided in Table 2.

Table 2. Detailed description of the four variants of TiGr4 used in the experiments.

\begin{tabular}{|c|c|c|c|c|}
\hline \multirow{2}{*}{ Variant No. } & \multicolumn{3}{|c|}{ Experiment-Samples } & \multirow{2}{*}{$\begin{array}{c}\text { Variant } \\
\text { Description }\end{array}$} \\
\hline & Material & Machining & Chip Thickness & \\
\hline 1 & \multirow{4}{*}{ Ti Gr4 } & \multirow{2}{*}{ turning } & thin $(\sim 0.1 \mathrm{~mm})$ & $\mathrm{V} 1$ \\
\hline 2 & & & coarse $(\sim 0.3-0.4 \mathrm{~mm})$ & $\mathrm{V} 2$ \\
\hline 3 & & \multirow{2}{*}{ milling } & thin $(\sim 0.1 \mathrm{~mm})$ & V3 \\
\hline 4 & & & coarse $(\sim 0.3-0.4 \mathrm{~mm})$ & $\mathrm{V} 4$ \\
\hline
\end{tabular}

Examples views of these chips are presented in Figure 2a (variant V2) and Figure $2 b$ (variant V4). Generally, the chips after turning $(\mathrm{V} 1, \mathrm{~V} 2)$ were long, twisted, ribbon-like and tangled, whereas the chips after milling $(\mathrm{V} 3, \mathrm{~V} 4)$ were short, flaky and loose. During the machining process the cooling by emulsion was not applied. Thus, titanium chips were not contaminated chemically by coolant. Moreover, the obtained chips were not significantly oxidized because their color remained typical for titanium, i.e., silvery-white. In contrast, the surface of the manufactured rods was significantly oxidized and, for this reason, these surfaces exhibited other, various colors.
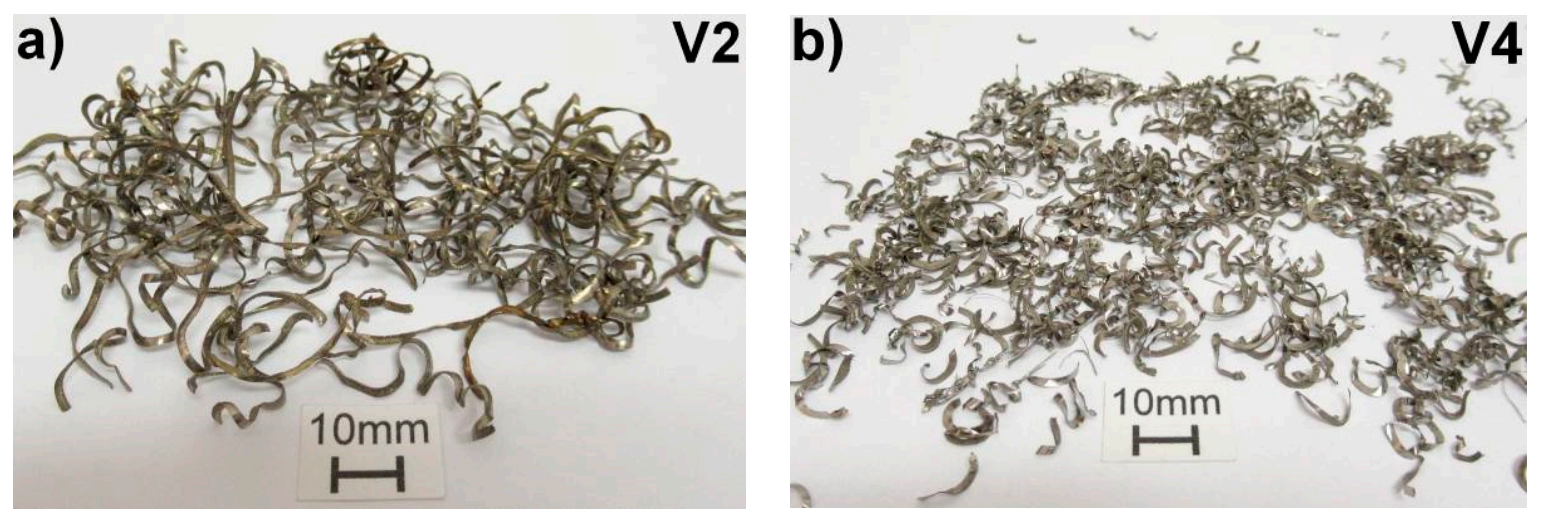

Figure 2. Macroscopic images of titanium Gr4 chips manufactured by machining: (a) coarse chips obtained by turningvariant V2, (b) coarse chips obtained by milling-variant V4.

In the context of chip microstructure, it should be explained that, during the applied machining, a very large plastic strain was introduced into each chip. This extremely high deformation changed the structures of the titanium significantly. Comparing the microstructure of the chips with those in the as-received state there were no equiaxial grains, and the grain boundaries were poorly visible. Instead, texture and deformation bands were 
visible, with only a few elongated grains. Some sample views of the microstructure of the chips are presented in Figure 3.
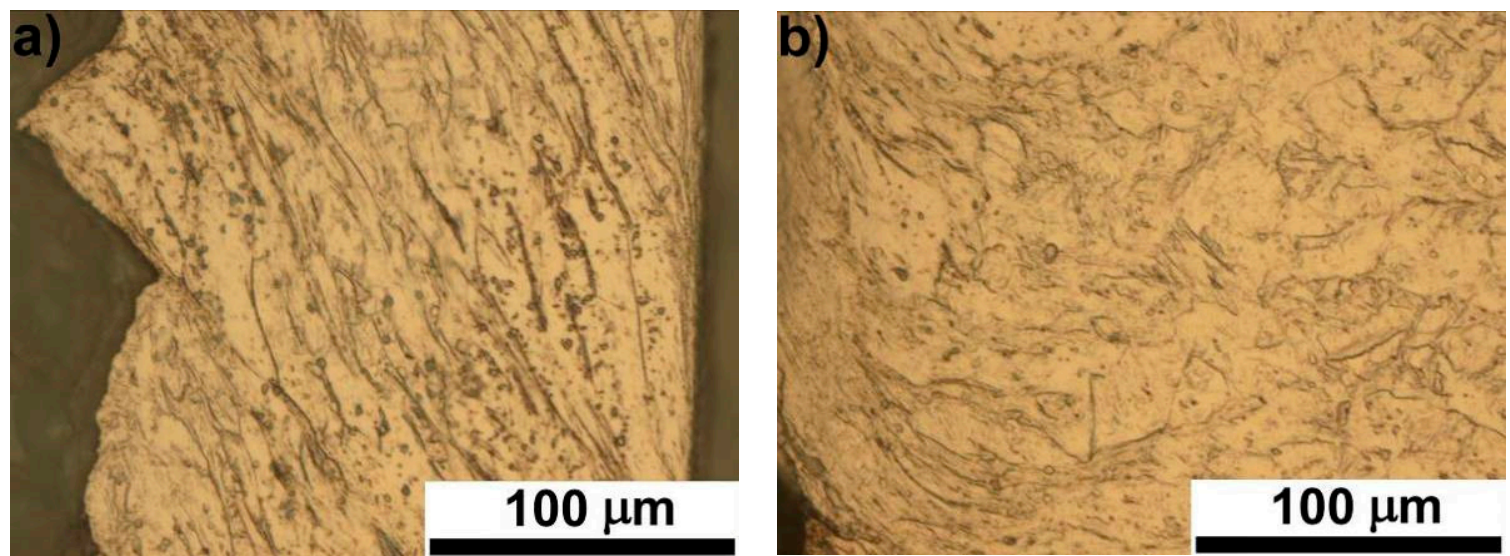

Figure 3. Sample views of the microstructures of the titanium Gr4 chips: (a) coarse chips obtained by turning-variant V2, (b) coarse chips obtained by milling-variant V4.

\subsection{Briquettes Obtained after Preliminary Consolidation of Chips}

In this step, the chips thus obtained were subjected to a preliminary consolidation using the upsetting method. The compaction process was carried out in a vertical position using special tools and a conventional hydraulic press. The applied stamp load was increased up to 30 tons. Each process was conducted in multiple strokes. In this way, cylindrical billets with a diameter of about $38 \mathrm{~mm}$, called "briquettes", were obtained. Each of the four types of chips was compacted separately, thus four individual briquettes were prepared.

The briquettes were characterized by a porous macrostructure consisting of deformed, tangled, bent and compacted chips. In this way, special, characteristic macrostructures consisting of chips were formed, where the chips had their own microstructure. For each type of chip, one separate briquette was obtained. Sample macroscopic views of the manufactured briquettes are presented in Figure $4 \mathrm{a}$ (variant V2) and Figure 4b (variant V4). As can be seen, the briquettes were solid and they formed the agglomerate, with relatively strong mechanical connections between particular macro-elements (chips).
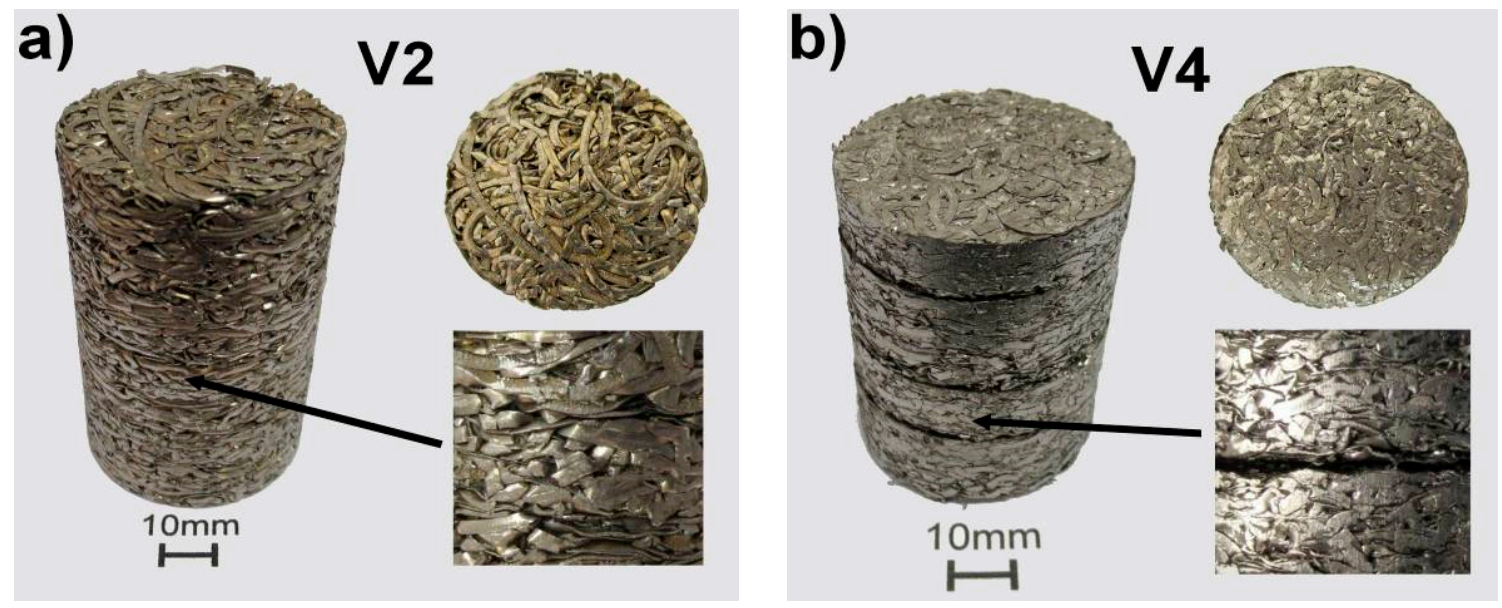

Figure 4. Sample views of titanium Gr4 briquettes obtained by preliminary consolidation: (a) briquette consisting of coarse chips after turning—variant V2, (b) briquette consisting of coarse chips after milling—variant V4. 
The briquettes obtained were subjected to the density measurements. Density was estimated based on the weight and dimensions of the briquettes (Table 3). It was observed that the densities of all of the briquettes were significantly lower than the theoretical density of solid commercial titanium $\left(4.51 \mathrm{~g} / \mathrm{cm}^{3}\right)$ and that of the rods produced by extrusion (about $4.50 \mathrm{~g} / \mathrm{cm}^{3}$, also see Table 7). This confirms that the briquettes were porous, and that there were some voids between the individual chips. The densities of the briquettes obtained from the chips after turning were lower than those of the briquettes obtained from the chips after milling, which is also confirmed by the macroscopic photos of the briquettes.

Table 3. Briquette density evaluated on the basis of mass and dimension measurements.

\begin{tabular}{ccccc}
\hline Sample & V1 & V2 & V3 & V4 \\
\hline Density $\left[\mathrm{g} / \mathrm{cm}^{3}\right]$ & 2.63 & 2.52 & 2.77 & 2.70 \\
\hline
\end{tabular}

\subsection{Heating of the Briquettes before Extrusion}

Before extrusion, each briquette was separately placed in a press chamber and was heated (through heating the chamber, together with the chamber), to a temperature of $350{ }^{\circ} \mathrm{C}$. Annealing at that temperature was then applied for $20 \mathrm{~min}$, after which the briquettes remained in the press chamber, which was not cooled or subjected to any other thermal process before extrusion. The heating was ongoing during the extrusion process. Thus, during the short time before the extrusion was initiated, the temperatures of the briquette and press chamber did not decrease.

The purpose of the annealing was: (1) to improve the plasticity of the chip-briquettes, (2) to reduce the extrusion force, (3) to facilitate the phenomenon of chip bonding, which is an important factor in the context of consolidating the chips and transforming them into solid form, and (4) to further facilitate, as an important part in the heat balance, the phenomenon of dynamic recrystallization.

During the extrusion process, due to friction and plastic deformation phenomena, the temperature of the processed titanium increased additionally probably by about $200-300{ }^{\circ} \mathrm{C}$, which further improved the ductility of the titanium and promoted bonding between the chips. On the other hand, both the rod-product and the die were cooled with water in the area of the die exit. Finally, in short, it can be assumed that the real-total extrusion temperature in the zone of deformation and die entry was about $600{ }^{\circ} \mathrm{C}$. This temperature also resulted in the desired phenomenon of dynamic recrystallization.

It is important to mention that, due to the initial annealing of the briquettes, the microstructure of the chips did not change essentially, and this treatment had no significant impact on the initial chip microstructure. Thus, the microstructure after annealing remained the same, and annealing was not a separate and additional step in the microstructure evolution.

\subsection{Rods Manufactured by Extrusion}

The final and key operation was direct extrusion with cyclic die rotation, realized alternately in both directions. Applied twist angle of die was $\pm 6^{\circ}$, whereas oscillation frequency of die was $5 \mathrm{~Hz}$. This unconventional plastic working process is commonly known as the KOBO method. Detailed information on this method was presented in the work [10]. The dies for extrusion of titanium chips were made of a special Inconel 718 alloy after solution and ageing. The chemical composition of the applied Inconel 718 was multi-element. However, the major elements were as follows (\%weight): $53.5 \mathrm{Ni}$; $18.61 \mathrm{Fe}$; 17.61 Cr; $5.05 \mathrm{Nb}$; $3.00 \mathrm{Mo}$. This chemical composition of the applied dies is important information in the context of the subsequent results of chemical composition tests of the rods-products.

The processes of extrusion (V1-V4) resulted in obtaining four separate volumetric products in the form of solid, bulk, consolidated rods. Their diameter was $8 \mathrm{~mm}$, and 
their length ranged from 400-600 mm (see example photos: Figure 5a-variant V2 and Figure $5 b-$ variant V3).

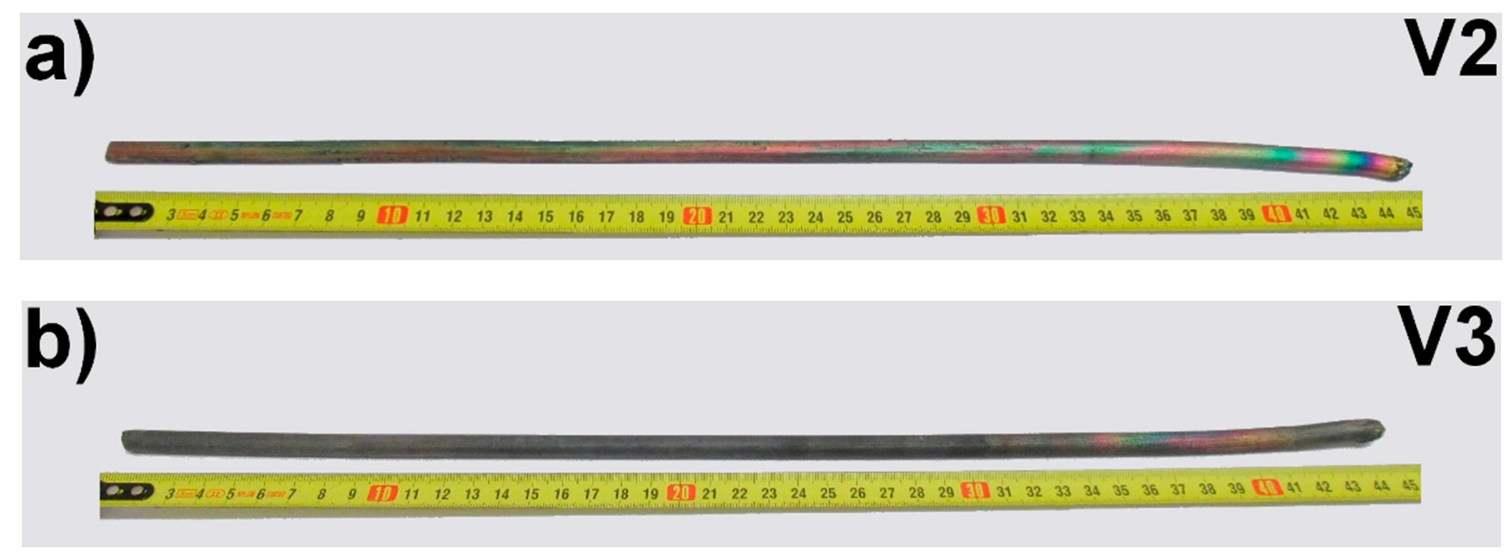

Figure 5. Example photos of final rods-products obtained by KOBO extrusion of briquettes: (a) variant V2 (Ti Gr4, coarse chips after turning), (b) variant V3 (Ti Gr4, thin chips after milling).

\subsection{X-ray Computer Tomography Examinations of Rods}

The rods obtained by processing the chips were subjected to structural investigations by X-ray computer tomography. This method made it possible to detect and visualize all spaces with a density other than that of titanium. These spaces then had a different color that creates a contrast. Thus, this technique reveals any matter different than titanium, i.e., (1) possible internal defects such as: pores, voids, delaminations or cracks, and (2) any possible metallic impurities resulting from the multi-stage processing. These nondestructive investigations were performed using the volumetric samples, so it was possible to precisely determine (in the all sample volume) the location of these areas and as well as to estimate their quantity. It should be emphasized that this technique has not previously been reported in the literature data regarded the recycling of chips. Using this computer tomography method, a special approach was taken, that made it possible to examine all the large volumes of the bulk, volumetric samples (length $50 \mathrm{~mm}$ and diameter $8 \mathrm{~mm}$ ).

On the basis of the set of photos obtained during the tests, three-dimensional models were generated that illustrated the internal structure of the tested samples. These models are semi-transparent. The results obtained are presented in Figure 6 (variants V1, V2, V3, V4). In order to illustrate the geometry and arrangement of individual areas, two views are presented: longitudinal and transverse. For each sample, two separate models were generated: one illustrating spaces with a density less than titanium (material $\rho<$ Ti $\rho$ ), and second illustrating spaces with a density greater than titanium (material $\rho>\mathrm{Ti} \rho$ ). Hence, the following colored spaces are visible in the models:

(a) semi-transparent, gray color-titanium,

(b) blue color- spaces less dense than titanium (material $\rho<$ Ti $\rho$ ). These spaces should be identified and interpreted as: closed pores, voids and/or cracks, or delamination. Thus this covers a wide group of defects that could have resulted from completely different causes. However, all of them are less dense than titanium. They appeared together and simultaneously, but can be distinguished on the basis of geometrical analysis and other microscopic research techniques,

(c) orange color-material with a density greater than titanium (material $\rho>$ Ti $\rho$ ). These spaces should be identified and interpreted as metallic impurities-inclusions coming from the die. These materials-particles were transferred during extrusion as a result of tribological phenomena.

Three-dimensional image reconstruction made it possible to conduct a quantitative morphometric analysis of the samples. The total percentage share of material whose density 
was less than that of titanium and the total percentage share of material whose density was greater than that of titanium were calculated. The results of these calculations are presented in Table 4 . The resolution of this investigation was $25 \mu \mathrm{m}$ (detection threshold) meaning, that any structural elements smaller than $25 \mu \mathrm{m}$ were not detected.

a) V1
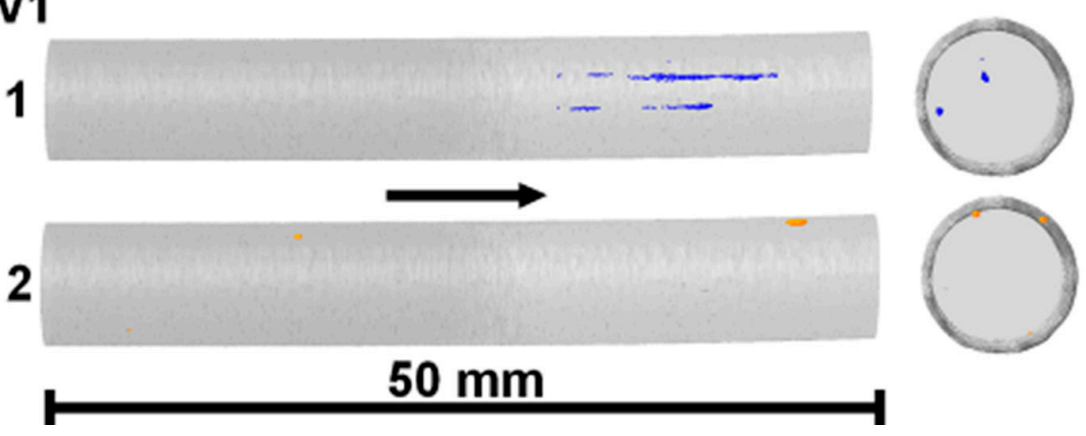

b) V2
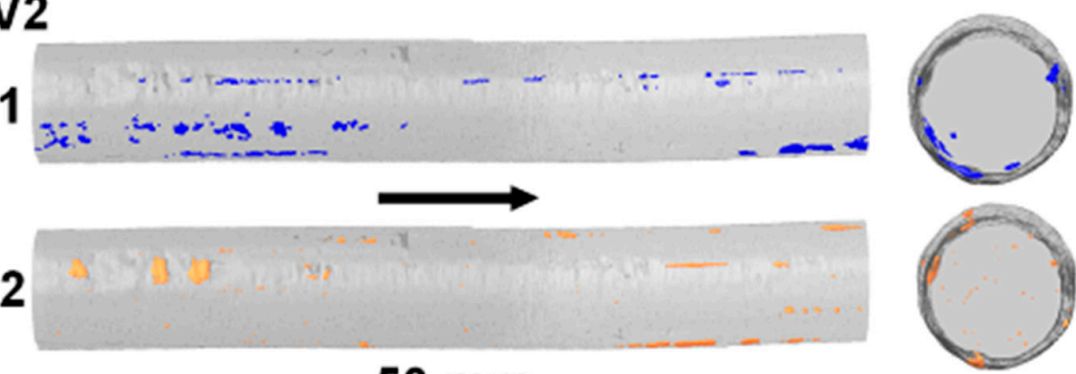

$50 \mathrm{~mm}$

c) V3

1

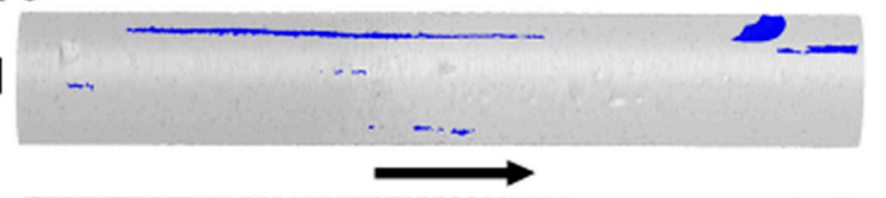

2
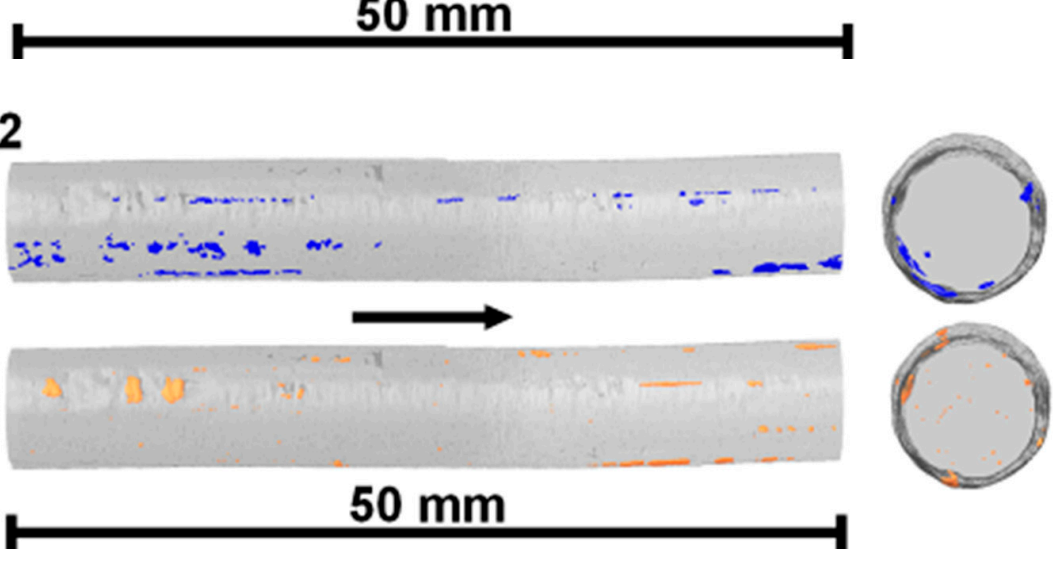

\section{(20)}


Table 4. Results of the quantitative calculation of the 3D models referring the total percentage share of material with density different than those of Ti. Analysis for spaces with a density less than that of titanium (material $\rho<$ Ti $\rho$, marked in blue on the 3D models) and for a density greater than that of titanium (material $\rho>$ Ti $\rho$, marked in orange on the 3D models). The applied resolution was $25 \mu \mathrm{m}$ (detection threshold), thus the calculation covers structural elements larger than $25 \mu \mathrm{m}$ only.

\begin{tabular}{ccc}
\hline Samples TiGr4 & Material $\rho<\operatorname{Ti} \rho[\%]$ & Material $\rho>\operatorname{Ti} \rho[\%]$ \\
\hline V1 & 0.02 & 0.01 \\
V2 & 0.11 & 0.10 \\
V3 & 0.19 & 0.20 \\
V4 & 0.54 & 0.24 \\
Average & 0.21 & 0.14 \\
\hline
\end{tabular}

The total percentage share of materials with a density less than that of titanium (material $\rho<$ Ti $\rho$ ) was calculated as the ratio of the sum of the volumes of all such materials $\left(\mathrm{V}_{\rho<\mathrm{Ti}}\right)$ to the volume of the entire sample $\left(\mathrm{V}_{\text {sample }}\right)$, i.e., $\left(\mathrm{V}_{\rho<\mathrm{Ti}} / \mathrm{V}_{\text {sample }}\right) * 100 \%$. Similarly, the total percentage share of materials with a density greater than that of titanium (material $\rho>\mathrm{Ti} \rho)$ was calculated as the ratio of the sum of the volumes of all such materials $\left(\mathrm{V}_{\rho>\mathrm{Ti}}\right)$ to the volume of the entire sample $\left(\mathrm{V}_{\text {sample }}\right)$, i.e., $\left(\mathrm{V}_{\rho>\mathrm{Ti}} / \mathrm{V}_{\text {sample }}\right) * 100 \%$.

All of the spaces (defects) with a density less than that of titanium were elongated and dragged along the rods in the direction of extrusion, which is typical for extrusion processes. The spaces were continuous or intermittent. On the transverse section, these spaces were characterized by small dimensions and were in the shape of a circle or ellipse. The geometry of these defects suggests that they are pores (voids), i.e., closed spaces filled with atmospheric air. Such structural elements may form when, during extrusion, air present in a briquette becomes trapped inside (blocked and closed). The porosity detected occurred in various locations distributed randomly.

Considering the samples of Ti Grade4 (V1-V4), the porosity was in the range of from $0.02-0.54 \%$, and the average was only $0.21 \%$, what is a favorable result. In these cases, good consolidated and compacted materials were obtained whose porosity was relatively small.

Despite the fact that, the densities of the briquettes obtained from the chips after turning were lower than those of the briquettes obtained from the chips after milling, it was observed that, the rods obtained from chips after turning had a slightly lower porosity than those obtained from chips after milling. The possible reason for this was that, during extrusion of the V3-V4 chips, air present in a briquette was more blocked. Besides, the V3-V4 chips were short, flaky and fine. This could have caused them to adhere more to the die. Thus the processing of V3-V4 chips may have been disrupted. In addition, the extrusion of coarse chips resulted in higher rod porosity than the extrusion of thin chips. This could be due to the greater stiffness of coarse chips and their higher resistance to plastic forming. This was probably due to the purity of titanium, and specifically to their relatively high yield point ( $\sim 500 \mathrm{MPa})$. With this high yield point, the thickness of the chips probably influence on the extrusion.

Nevertheless, it should be emphasized that the differences in porosity obtained for some individual variants were relatively small. In addition, the specific nature of such plastic forming is that, the porosity in different areas of the rods can differ slightly. Therefore, the most reasonable conclusion is that, regardless of chip type, the porosity of the rods obtained using the $\mathrm{KOBO}$ method is in a narrow range and does not exceed a certain, relatively small limit. The porosity of the Ti Gr4 rods did not exceed $0.6 \%$. Hence, it can be concluded that processing titanium chips by preliminary upsetting followed by $\mathrm{KOBO}$ extrusion makes it possible to obtain rod-products whose porosity is less than $0.6 \%$.

The defects with a density greater than that of titanium (metallic impurities-inclusions, material $\rho>$ Ti $\rho$, orange color on the 3D models) did not occur randomly. They were revealed on the perimeter, i.e., on the external surface of the rods. Exception could be sample V2, which exhibited some insignificant number of such defects inside the rod also. 
Defects with a density greater than Ti were elongated and dragged along the rods, i.e., in the direction of extrusion, which is typical for such processes. It was observed that the sample V1 exhibited a quantity of metallic defects close to zero. In this case, porosity was close to zero also, thus very high quality product was obtained, which level of defects was insignificantly low. In the remaining cases (V2, V3, V4), the amount of impurity was higher, but still relatively low.

Taking into account all of the samples of Ti Gr4 (V1-V4), the impurities ranged from $0.01-0.24 \%$ (average $0.14 \%$ ). These results are satisfactory and (despite the difficult tribological conditions associated with extrusion) confirm the high purity of the products obtained. Generally, the extrusion of Ti Gr4 resulted in some small amount of impurities along the rod's surface caused by the metals being transferred from the dies. This was because tribological wear of the dies and, thus, transfer of metals from the dies to the surface of the rods. Generally, it was found that, regardless of the type of chips, the impurities in the rods obtained by the KOBO method were in a narrow range and did not exceed a relatively small limit of $0.3 \%$.

As stated previously, the rods obtained from chips after turning had a slightly lower porosity than those obtained from chips after milling. Similarly, it was observed, that these rods obtained from chips after turning had also a smaller amount of impurities than those obtained from chips after milling. The possible reason for this was that, in the V3-V4 case, thin and finest chips more adhered to the die. Thus, there was a greater wear of the front surface of the dies and greater transferring of particles from the dies.

In addition, analogous to the results of porosity, the extrusion of the thin chips resulted in slightly less impurity than the extrusion of the coarse chips. It results from greater difficulty in deforming coarse chips. Nevertheless, it should be emphasized that the differences obtained for individual variants were relatively small. In addition, a characteristic feature of such processing is that the share of defects in different areas of a rod can differ slightly.

Some relationship between porosity and defects having a density greater than that of Ti has been observed. The samples with higher porosity also had a higher content of non-Ti metals. This suggests the influence of die wear on the quality of the rod obtained.

Summing up, a dispersed form (chips) was successfully transformed into new, consolidated, near fully dense and compacted solid state structures. Based on the computer tomography examination, in the manufactured rods, no initial chip boundaries were revealed. Moreover, the voids present between the chips in the briquettes were not detected too. In other words, the macrostructures of the briquettes (consisting of chips) were fully processed.

\subsection{Chemical Analysis of the Surfaces of the Rods by XRF}

The computer tomography research revealed the presence on the rod's surface of some particles characterized by a density higher than that of titanium (material $\rho>\operatorname{Ti} \rho$ ). To identify and verify these materials, an analysis was performed using X-ray fluorescence spectrometry. The results of the chemical analysis of the surfaces of the manufactured rods are presented in Table 5. The applied XRF technique allowed identification of elements ranging from magnesium to uranium, inclusive. This means that, using XRF, it was impossible to detect light elements such as oxygen, hydrogen, carbon and nitrogen present in Ti Gr4. Therefore, the XFR studies did not include these elements.

Based on the chemical tests conducted, additional, foreign metallic elements- $\mathrm{Ni}, \mathrm{Nb}$, Mo and Fe were found on the external cylindrical surfaces of the rods (note, Fe is part of the chemical composition of Ti Gr4 simultaneously). A chemical analysis confirmed that these particles-structural components on the rod's surface were metallic impurities-inclusions. According to the results obtained using computer tomography, each of these elements had a density greater than that of titanium. These were defects, and should be interpreted as impurities that came from the die. The dies for the KOBO extrusion were made of a special Inconel 718 alloy containing exactly such metallic elements. Hence, these metals were transferred from the die during the extrusion process as an effect of tribological phenomena. 
These multicomponent (multimetallic) particles were formed, in some places on the surface of the rods, as a result of mixing, bonding, welding and grafting of the titanium with the Inconel alloy.

Nevertheless, it should be emphasized that the chemical analysis confirmed the results obtained by tomography, that quantitative content of these impurities was relatively small and insignificant. Further, the small amounts of these foreign metals occurred on the surface of the rods mainly, and could easily be removed by surface treatment. Our examinations by XRF of the transverse and longitudinal sections of the rods did not reveal the presence of such impurities inside. The only exception was the sample V2 on the transverse section (detected $\mathrm{Cr}=0.42 \pm 0.12 \% \mathrm{wt}$.) and the sample V3 on the transverse section (detected $\mathrm{Cr}=0.43 \pm 0.12 \% \mathrm{wt}$.; $\mathrm{Mo}=0.02 \% \mathrm{wt}$.) where the some insignificant amount of foreign elements were transferred inside the rod also.

Table 5. Results of chemical analysis performed on the external cylindrical surfaces of the manufactured rods. Results obtained by X-ray fluorescence spectrometry. Description: [\%wt.]—content in weight percent, Av—average value. Statisticnumber of detected cases per two measurements (two surface measurements were made for each variant). Error of measurements: $\mathrm{Ti} \pm 0.05 ; \mathrm{Fe} \pm 0.04$.

\begin{tabular}{cccccccc}
\hline \multicolumn{2}{c}{ Additional Element } & $\mathbf{F e}$ & $\mathbf{N i}$ & $\mathbf{M o}$ & $\mathbf{N b}$ & $\mathbf{C r}$ & $\mathbf{T i}(\mathbf{B a s e})$ \\
\hline \multicolumn{2}{c}{$\begin{array}{c}\text { Range [\%wt.] } \\
\text { (average) }\end{array}$} & $\begin{array}{c}0.28-3.42 \\
(\mathrm{Av}=1.181)\end{array}$ & $\begin{array}{c}0.00-0.24 \\
(\mathrm{Av}=0.120)\end{array}$ & $\begin{array}{c}0.00-0.06 \\
(\mathrm{Av}=0.015)\end{array}$ & $\begin{array}{c}0.00-0.02 \\
(\mathrm{Av}=0.007)\end{array}$ & $\begin{array}{c}0.00 \\
(\mathrm{Av}=0.00)\end{array}$ & $\begin{array}{c}96.26-99.72 \\
(\mathrm{Av}=98.677)\end{array}$ \\
\hline \multirow{3}{*}{ Statistics } & $\mathrm{V} 1$ & $2 / 2$ & $2 / 2$ & $0 / 2$ & $0 / 2$ & $0 / 2$ & $2 / 2$ \\
\cline { 2 - 8 } & $\mathrm{V} 2$ & $2 / 2$ & $2 / 2$ & $1 / 2$ & $1 / 2$ & $0 / 2$ & $2 / 2$ \\
\cline { 2 - 8 } & $\mathrm{V} 3$ & $2 / 2$ & $2 / 2$ & $1 / 2$ & $1 / 2$ & $0 / 2$ & $2 / 2$ \\
\hline
\end{tabular}

\subsection{Chemical Analysis of the Rods by SEM-EDS}

To extend the analysis of chemical purity/contamination of the manufactured rods, the chemical microanalysis using SEM-EDS was also used (Table 6). The results showed, that the tested areas selected from manufactured rods, in a total of fourteen out of sixteen cases, consist entirely of titanium and are not contaminated with other elements. Although insignificant amount of $\mathrm{Si}$ was detected in several cases, it should not be taken into account. Silicon occurs only superficial. Its presence is the result of sample preparation, i.e., it is a polishing residue. In only two out of sixteen cases, some amount of $\mathrm{Ni}$ and $\mathrm{Cr}$ were detected. These are the only contaminants found. Foreign elements $\mathrm{Ni}$ and $\mathrm{Cr}$ come from the dies and were detected only on the circuit of the samples (rods).

It should be explained that, according to the Ti Grade4 standard, this grade contains about $0.8 \%$ wt. solid solutes elements other than Ti, such as: $\mathrm{Fe}$, and light elements: $\mathrm{O}$, $\mathrm{N}, \mathrm{H}, \mathrm{C}$ (see Table 1). However, in this case, their presence is not detectable by SEM-EDS. Based on the SEM-EDS investigation, it was theoretically possible to detect light elements such as $\mathrm{O}, \mathrm{H}, \mathrm{N}$ and $\mathrm{C}$. However, they were not detected (the content was evaluated as zero) because their quantity and concentration were apparently too low. Thus, this content had to be relatively small, and, at the same time, similar to the Ti in the as received state. In the context of: contamination, content of light metal and oxidation, it is worth explaining, that the microscopic observations did not reveal the presence of the oxide lattice in the manufactured materials.

Generally, the results of the chemical composition tests obtained by the SEM-EDS method are consistent with the results obtained using computer tomography and the XRF method. However, some differences resulted from a different testing method and different samples (external cylindrical surfaces versus metallographic specimen from the sections). 
Table 6. Results of the chemical composition obtained using SEM-EDS technique. Samples V1-V4 analyzed on the transverse section and on the longitudinal section in different areas (circuit, center). Error of measurements: $\pm 0.66 \%$ wag.

\begin{tabular}{|c|c|c|c|c|c|c|c|c|}
\hline \multirow{2}{*}{ Element [\%] Weight } & \multicolumn{2}{|c|}{ V1 Transverse } & \multicolumn{2}{|c|}{ V2 Transverse } & \multicolumn{2}{|c|}{ V3 Transverse } & \multicolumn{2}{|c|}{ V4 Transverse } \\
\hline & Circuit & Center & Circuit & Center & Circuit & Center & Circuit & Center \\
\hline $\mathrm{Ti}$ & 100 & 100 & 99.77 & 99.72 & 100 & 99.77 & 100 & 100 \\
\hline $\mathrm{Ni}$ & - & - & - & - & - & - & - & - \\
\hline $\mathrm{Fe}$ & - & - & - & - & - & - & - & - \\
\hline $\mathrm{Cr}$ & - & - & - & - & - & - & - & - \\
\hline $\mathrm{Nb}$ & - & - & - & - & - & - & - & - \\
\hline Mo & - & - & - & - & - & - & - & - \\
\hline $\mathrm{Si}$ & - & - & 0.23 & 0.28 & - & 0.23 & - & - \\
\hline Other total & - & - & - & - & - & - & - & - \\
\hline \multirow{2}{*}{ Element [\%] Weight } & \multicolumn{2}{|c|}{ V1 Longitudinal } & \multicolumn{2}{|c|}{ V2 Longitudinal } & \multicolumn{2}{|c|}{ V3 Longitudinal } & \multicolumn{2}{|c|}{ V4 Longitudinal } \\
\hline & Circuit & Center & Circuit & Center & Circuit & Center & Circuit & Center \\
\hline $\mathrm{Ti}$ & 100 & 100 & 93.59 & 100 & 90.41 & 100 & 99.68 & 99.71 \\
\hline $\mathrm{Ni}$ & - & - & 4.97 & - & 7.50 & - & - & - \\
\hline $\mathrm{Fe}$ & - & - & - & - & - & - & - & - \\
\hline $\mathrm{Cr}$ & - & - & 1.44 & - & 2.09 & - & - & - \\
\hline $\mathrm{Nb}$ & - & - & - & - & - & - & - & - \\
\hline Mo & - & - & - & - & - & - & - & - \\
\hline $\mathrm{Si}$ & - & - & - & - & - & - & 0.32 & 0.29 \\
\hline Other total & - & - & - & - & - & - & - & - \\
\hline
\end{tabular}

\subsection{Density Measurements}

The manufactured materials were also subjected to density measurements in order to evaluate their structural quality and the consolidation effect. Ti Gr4 sample in the as-received state was also tested as references for the materials after processing. The density result obtained for titanium in the as-received state was designated as $100 \%$, and then the density results for titanium after processing $(\mathrm{V} 1-\mathrm{V} 4)$ were calculated in relation to the density of Ti in the as-received state, described as percentages, and defined as relative density.

The results show that all the rods obtained (V1-V4) were characterized by the typical, correct density for solid titanium (Table 7). The theoretical-nominal density of solid commercial Ti is $4.51 \mathrm{~g} / \mathrm{cm}^{3}\left(4.507 \mathrm{~g} / \mathrm{cm}^{3}\right)$, and may differ slightly depending on purity and temperature. The values of densities obtained were only slightly and insignificantly lower $\left(0.01 \mathrm{~g} / \mathrm{cm}^{3}\right)$ than the theoretical density of solid titanium. This could be the effect of the minimal porosity revealed in the computer tomography investigations. The density of the Ti Gr4 rods remained the same, at $4.50 \mathrm{~g} / \mathrm{cm}^{3}$ for all V1-V4 cases. The densities of the V1-V4 rods were significantly higher than those of the briquettes (about $3.00 \mathrm{~g} / \mathrm{cm}^{3}$, see Table 3), which is another evidence of the transformation of the chips.

Although the plastic shaping and deformation of Ti Gr4 is more difficult than other grades of Ti, surprisingly, the Ti Gr4 had practically a correct density. In addition, the density of the Ti Gr4 rods was correct, despite the fact that the porosity of these rods was higher than $0.00 \%$. These inconsistent differences in the porosity-density results may be explained by the fact, that these results are influenced by surface contamination of Ti Gr4 with metals-particles heavier than $\mathrm{Ti}$ (which inflate the density results). No clear and significant effect of: (1) chips type (turning, milling) or (2) chips thickness on the density results was observed. 
Referring the obtained results to solid $\mathrm{Ti}$ in the as-received state, the $\mathrm{Ti} \mathrm{Gr} 4$ rods (V1-V4) exhibited a very high relative density equal $99.78 \%$. Comparing these results to the literature, for example, in work [9], Ti6Al4V chips were processed by ECAP, and relative densities of from $92-99.9 \%$ were obtained, depending on: the number of ECAP passes, the value of back pressure, and the processing temperature. Whereas Ti Gr2 chips obtained by milling and processed by ECAP resulted in products with a density ranging from 4.50 to $4.53 \mathrm{~g} / \mathrm{cm}^{3}[7]$.

In summary, the results of the density measurements confirmed that the applied extrusion made it possible to transform the briquettes (having a porous structure) into solid, volumetric, near fully dense and condensed materials. The densities of the manufactured rods were very close to that of commercial titanium available in the trade, and quite satisfactory.

Table 7. Results of density measurements $\left[\mathrm{g} / \mathrm{cm}^{3}\right]$ obtained for Ti Gr4 and Ti hp 99.99 performed using the Archimedes method.

\begin{tabular}{cccccc}
\hline Sample Ti Gr4 & As-Received & V1 & V2 & V3 & V4 \\
\hline Measurement No.1 & 4.52 & 4.50 & 4.50 & 4.50 & 4.49 \\
\hline Measurement No.2 & 4.51 & 4.49 & 4.50 & 4.50 & 4.50 \\
\hline Measurement No.3 & 4.51 & 4.50 & 4.50 & 4.50 & 4.50 \\
\hline Average density & 4.51 & 4.50 & 4.50 & 4.50 & 4.50 \\
\hline Relative density [\%] & 100.00 & 99.78 & 99.78 & 99.78 & 99.78 \\
\hline
\end{tabular}

\subsection{Structural Investigations of Rods Using Light Microscopy}

Our research of the manufactured rods showed that in all variants (V1-V4) a grained, solid state structure typical of polycrystalline metals was obtained. Exemplary and representative photos of rod's microstructures are presented in Figure 7 (transverse section) and in Figure 8 (longitudinal section). It should be emphasized, that the grained microstructures obtained are typical of commercial titanium, and were present in the as-received Ti as well. For each variant, after the metallographic observations the grain size and the grain shape were calculated. The results of the stereological analysis of these materials are summarized in Table 8.

Generally, for each rod (V1-V4), a very homogeneous microstructure with equiaxed grains was obtained. The microstructures of all the rods were characterized by similar grains. On the entire tested surface of each sample, there were grains of very similar size and shape, which was confirmed by the small values of the SD and CV coefficients, and similar values of $\alpha$ parameters and $\beta$ parameters that were close to " 1 ". For each variant, the entire surface of the sample exhibited the same, homogeneous microstructure. In other words, there were no differences between the various regions of the samples.

For each variant, transverse and longitudinal sections were tested. Comparing both these sections of a given variant, it was found that in each case the microstructure was the same. On the longitudinal sections no effects of texture or elongated grains were observed such as often occur in products such as rods.

A characteristic feature of all revealed microstructures (V1-V4) was that they had a very small grain size, significantly smaller than the grains of the titanium in the asreceived state. This was the effect of a dynamic recrystallization that took place during the extrusion process, and of a lack of subsequent grain growth. Grain growth was deliberately limited by the: (1) short extrusion time, (2) cooling of the rods at the die exit, and (3) the optimal temperature of the briquettes. In machining, the chip formation occurs by shear deformation, which is concentrated in a narrow deformation zone inside the treated material. Hence, during each single machining pass, a very large plastic strain is introduced into each chip $[10,20,21]$. As a result of this extremely high deformation, the structure of the material changes significantly, and becomes different than in the as-received state before 
machining (see Figure 3). In chip microstructures, there are no equiaxed grains, and the grain boundaries are often invisible. Instead, there are texture and deformation bands. Since the equiaxial grains visible in the rods did not come from the chips, they had to be the result of dynamic recrystallization, which must have occurred during the extrusion of the briquettes. The chip structure is in a metastable state, the chips contain some stored energy and structural defects. In the next stage, when the chips were extruded using appropriate parameters (temperature, strain), this made the initiation of dynamic recovery and the recrystallization of the titanium.

Another reason for a hypothesis on recrystallization is the presence of the same equiaxed grain shape in both sections. In the longitudinal section, the grains are not elongated in the direction of extrusion. Extruding at a lower temperature without recrystallization leads to crystallographic texturing with strongly deformed, stretched grains, such were not present in the recycled titanium. Thus, it can be assumed that a dynamic recrystallization occurred during the extrusion process. The same conclusion was reached in work [2], where aluminum chips were recycled.

In the context of the grain microstructure obtained by chip recycling, the literature reports, for example, on the ECAP method applied to recycle pure Ti Gr2 chips after milling [7]. There, as well as in our work, it was observed that very small grains (with an average size of $\sim 0.8 \mu \mathrm{m}$ ) were obtained at an extrusion temperature of $450{ }^{\circ} \mathrm{C}$, while grains of about $3.9 \mu \mathrm{m}$ were obtained at a higher temperature of $590^{\circ} \mathrm{C}$. It was also found that dynamic recovery and recrystallization processes may have occurred.
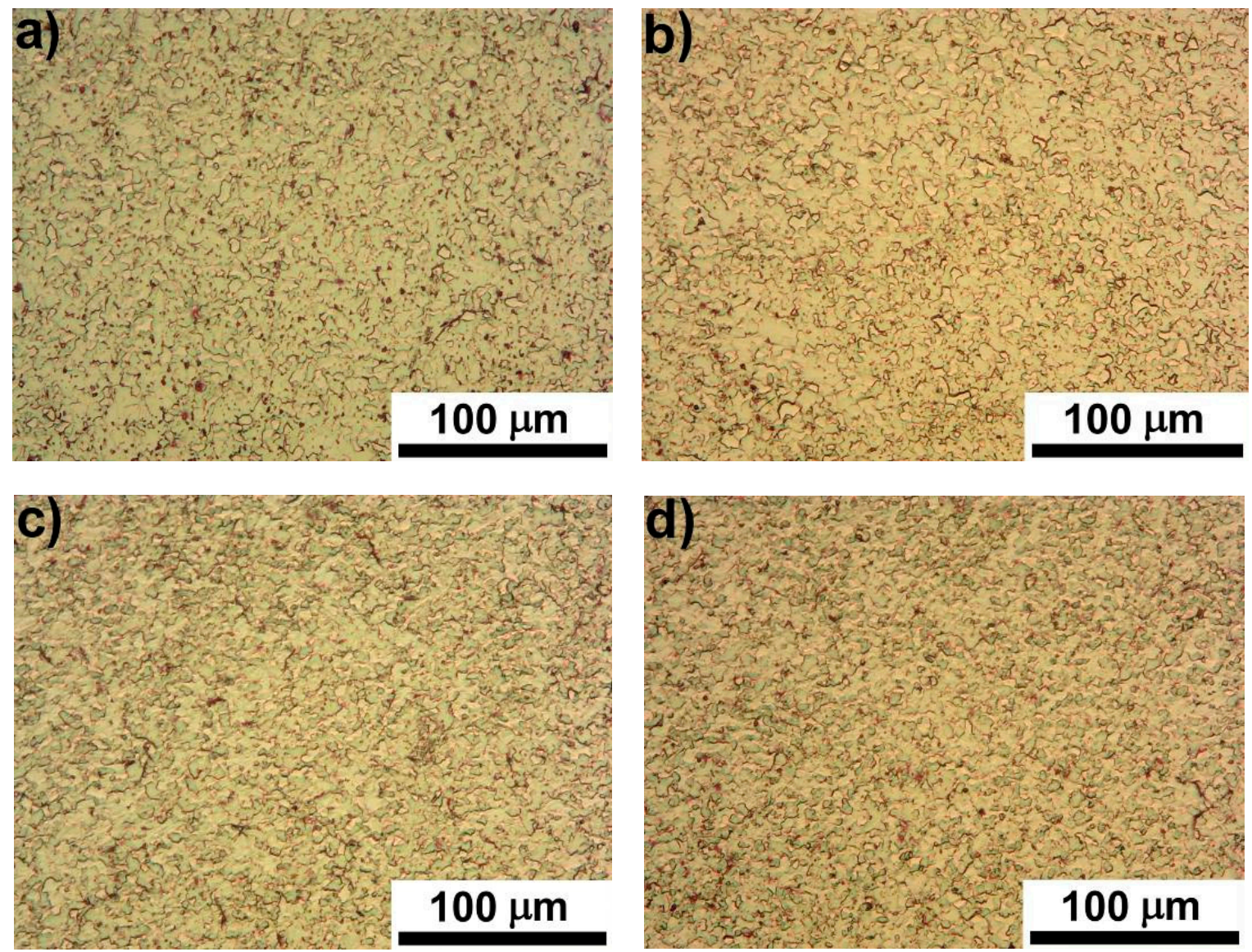

Figure 7. Microstructures of manufactured Ti Gr4 rods revealed by etching, transverse section, light microscopy: (a) variant $\mathrm{V} 1,(\mathbf{b})$ variant $\mathrm{V} 2,(\mathbf{c})$ variant $\mathrm{V} 3,(\mathbf{d})$ variant $\mathrm{V} 4$. 

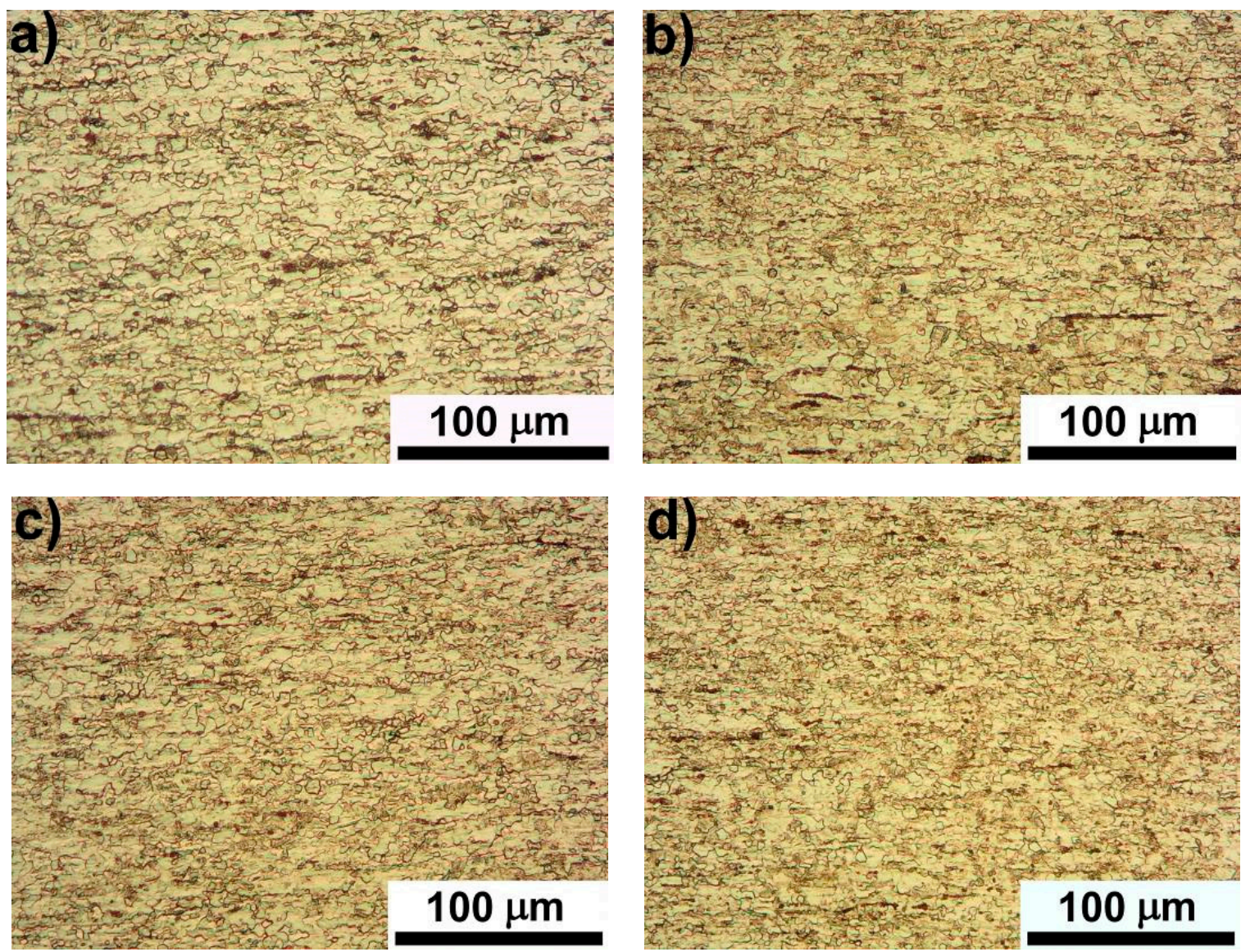

Figure 8. Microstructures of manufactured Ti Gr4 rods revealed by etching, longitudinal section, light microscopy: (a) variant V1, (b) variant V2, (c) variant V3, (d) variant V4.

In the case of Ti Gr4 (V1-V4), by comparing the four individual variants with each other it was found that the type of chips (turning, milling) and their thickness (thin, coarse) did not affect the microstructures of the obtained rods, since all four microstructures were characterized by practically the same grain size and grain shape (Table 8).

Table 8. Results of the stereological analysis of the microstructure of Ti Gr4, where: $\mathrm{E}\left(\mathrm{d}_{2}\right)$-average grain size, SD—standard deviation, $\mathrm{CV}$-coefficient of variation, $\alpha$ and $\beta$-shape factors (a description of the stereological parameters is included in chapter "Investigation methods").

\begin{tabular}{cccccc}
\hline Ti Gr4 Samples (Chips)_Section & $\mathbf{E}\left(\mathbf{d}_{\mathbf{2}}\right)$ & $\mathbf{S D}\left(\mathbf{d}_{\mathbf{2}}\right)$ & $\mathbf{C V}\left(\mathbf{d}_{\mathbf{2}}\right)$ & $\alpha$ & $\beta$ \\
\hline As-received-transverse & 32.09 & 9.71 & 0.30 & 1.32 & 1.20 \\
\hline As-received-longitudinal & 27.78 & 8.34 & 0.30 & 1.29 & 1.17 \\
\hline V1 (turning, thin)—transverse & 4.70 & 0.95 & 0.20 & 1.28 & 1.16 \\
\hline V1 (turning, thin)-longitudinal & 4.06 & 1.01 & 0.25 & 1.27 & 1.15 \\
\hline V2 (turning, coarse)-transverse & 4.26 & 0.86 & 0.20 & 1.25 & 1.14 \\
\hline V2 (turning, coarse)-longitudinal & 3.92 & 1.12 & 0.29 & 1.26 & 1.14 \\
\hline V3 (milling, thin)-transverse & 3.44 & 0.84 & 0.25 & 1.24 & 1.13 \\
\hline V3 (milling, thin)-longitudinal & 3.43 & 0.91 & 0.27 & 1.26 & 1.14 \\
\hline V4 (milling, coarse)-transverse & 3.72 & 0.71 & 0.19 & 1.28 & 1.14 \\
\hline V4 (milling, coarse)-longitudinal & 3.10 & 0.72 & 0.23 & 1.28 & 1.15 \\
\hline
\end{tabular}


Since in all of the variants similar final microstructures were obtained, it can be stated that the most important factors determining the final microstructures were the parameters of the extrusion process. It should be emphasized that, in our experiments, the extrusion parameters were the same for all four variants.

The relatively small magnification applied in Figures 7 and 8 made it possible to show the homogeneity of the V1-V4 microstructures, because the area of the image (where the average grain size was only about $4 \mu \mathrm{m}$ ) contained a relatively large number of grains. This magnification was also adjusted to the microstructure of the $\mathrm{Ti}$ in as-received state, which was characterized by a significantly larger grain size (averaging about $30 \mu \mathrm{m}$, Figure 1). Thus, it was possible to easily compare the as-received microstructures with those of the manufactured rods. However, when applied to Figures 7 and 8, this magnification did not permit an accurate analysis of the individual grains because the structures V1-V4 were too fine-grained. For this reason, observations were also made at higher magnifications (Figure 9). Figure 9 shows some sample microstructures (V2, V4) presented at a higher magnification where individual, single grains are visible.
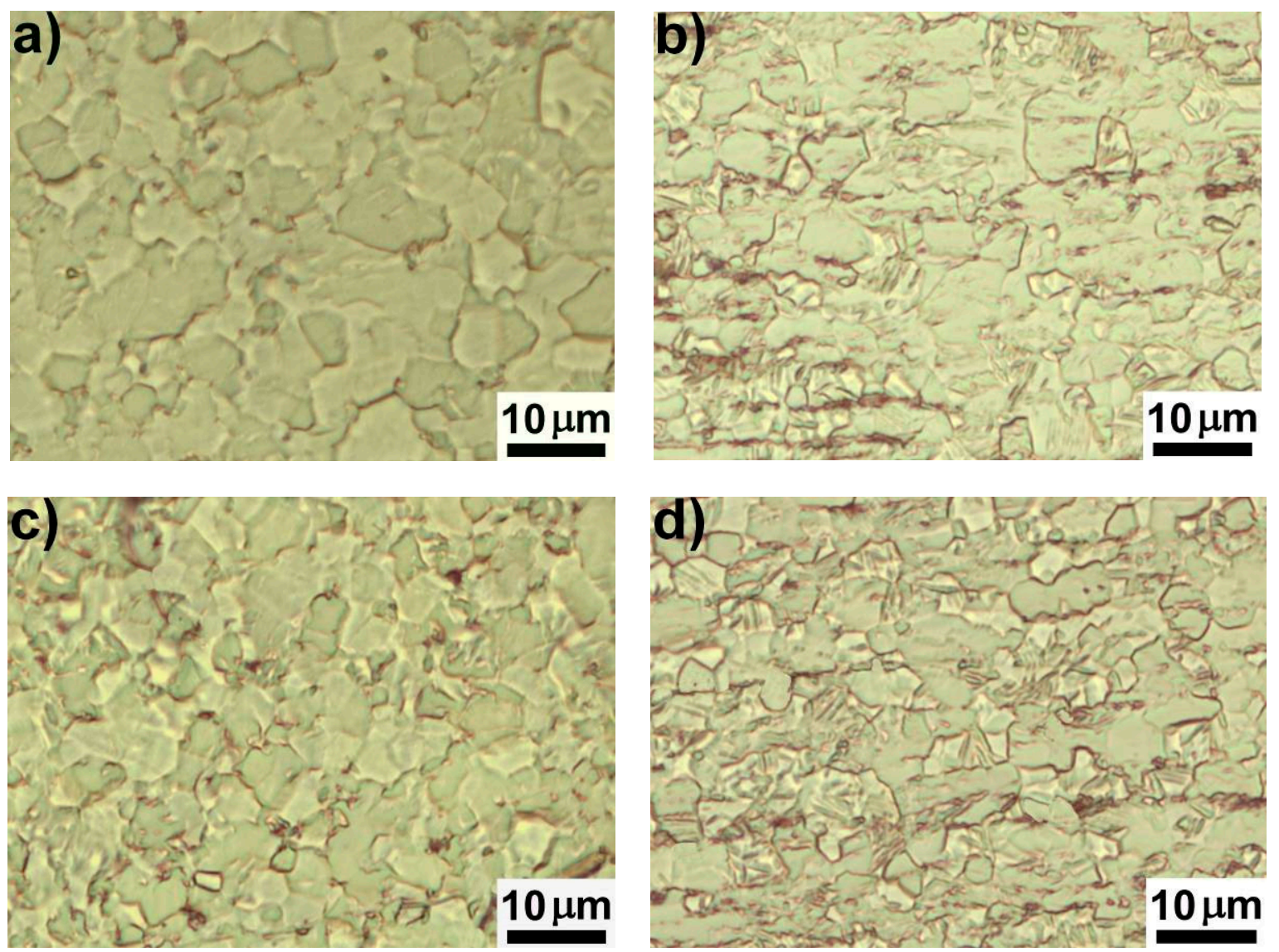

Figure 9. Microstructures of manufactured Ti Gr4 rods revealed by etching, visible under higher magnification: (a) variant V2, transverse section, (b) variant V2, longitudinal section, (c) variant V4, transverse section, (d) variant V4, longitudinal section.

Summarizing this chapter, in all of the manufactured rods new solid, grained, monolithic structures without the initial chips boundaries were obtained. This confirms that atomic (metallic) bonds between the chips were formed, and the chips became bonded. Due to adhesion and cohesion, consolidation phenomena took place. 


\subsection{Structural Investigations of Rods by Scanning Electron Microscopy (SEM)}

The SEM investigations were conducted in order to confirm or/and obtain other information about the manufactured structures. This technique makes it possible to analyze recycled structures precisely, what has been also demonstrated by others authors who investigated pores and bonds [17,18].

The SEM investigations (conducted at different magnification) confirmed that all of the materials obtained (V1-V4) were near fully consolidated, as well as near fully dense. The dispersed form of the chips was transformed into bulk, solid materials. Sample results obtained using SEM are presented in Figure 10 (V1 variant). The monolithic, compact and homogeneous materials with no visible initial chip boundaries were observed. No voids were observed as had been present between the chips in the briquettes. In other words, no macrostructure consisting of chips, as was the case in the briquettes, was observed. As can be seen from the SEM pictures, the chips were fully processed and the briquettes were transformed into a new, solid structure with a new bonding on the atomic scale. Moreover, no delamination effect caused by an oxide layer was observed. Such defects can occur because at elevated temperatures titanium chips are subjected to oxygenation phenomena due to the machining and extrusion. It should be emphasized that the plastic working process applied (conducted at an elevated temperature, i.e., without remelting) considerably reduced chip oxidation and its negative effect on structure. Similarly, as in previous investigations, it can be concluded that adhesion and bonding between the initial chip surfaces occurred.
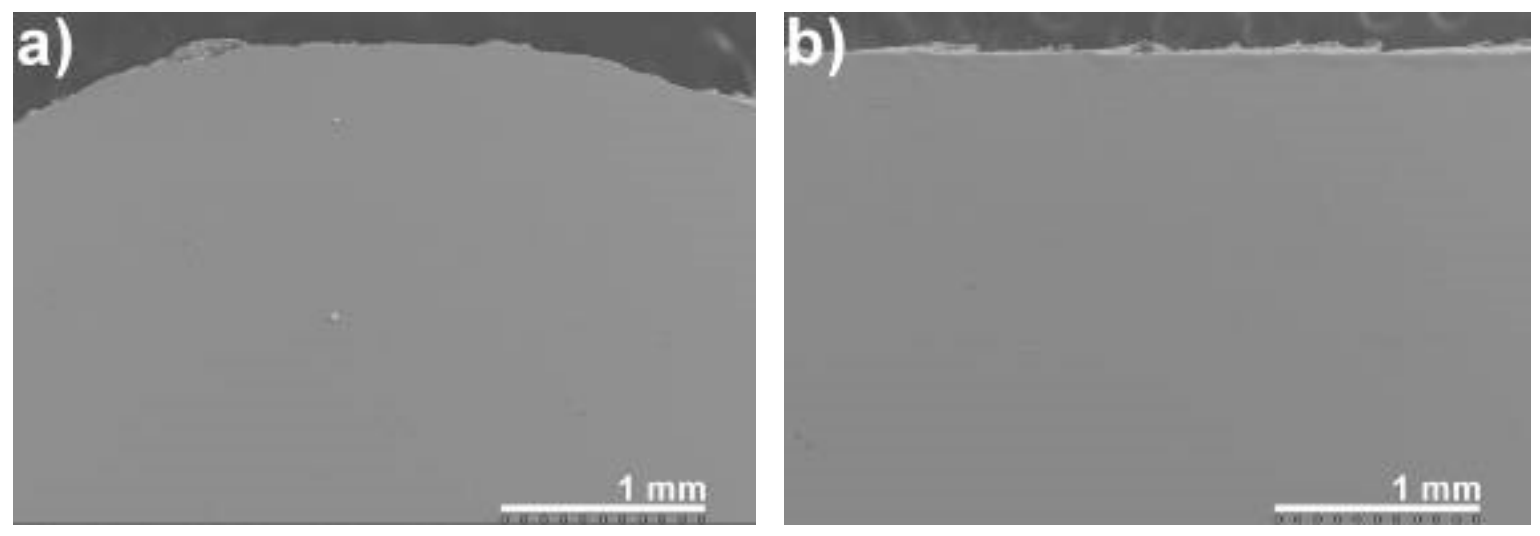

Figure 10. The results obtained for the polished samples using the SEM technique. Variant V1: (a) transverse section, (b) longitudinal section.

However, the obtained materials were also characterized by not numerous voids. The SEM structural observations made it possible to analyze the voids detected during the computer tomography examination. It was observed that these structural defects were three-dimensional. Some of them occurred in groups, and some separately. The voids in the transverse section of the samples were relatively equiaxial, whereas in the longitudinal section they were elongated and arranged in lines according to the direction of extrusion. The voids were surrounded by smooth, rounded surfaces. They were not fracture surfaces, delaminations or fragments of not-bonded chips. It was found that they were the micropores, i.e., enclosed spaces inside the material filled with atmospheric air. This air came from the briquette voids, and has been blocked-trapped in the material during extrusion. Sample results of these structural defects are presented in Figure 11. 

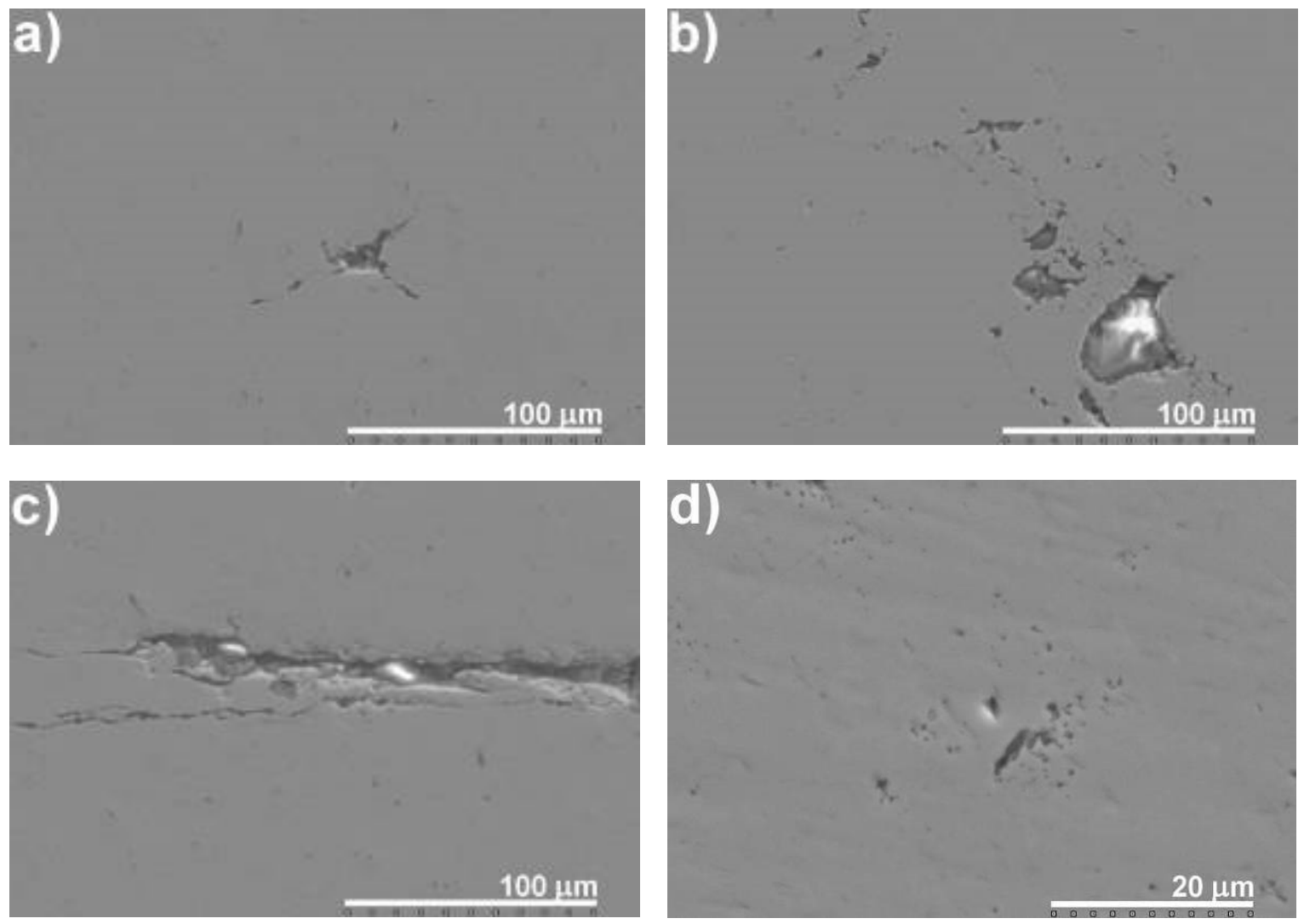

Figure 11. Example results of structural defects visible using SEM: (a) V2 transverse section, (b) V3 transverse section, (c) V2 longitudinal section, (d) another area of V2 transverse section visible in higher magnification.

As can be seen in the SEM pictures, the size of the pores is different. Including computer tomography results the size of the pores is in a very wide range (from a few micrometers to several millimeters). When using the computer tomography technique, pores smaller than $25 \mu \mathrm{m}$ were not revealed (detection threshold), because that research concerning examining the large volumes of the bulk, volumetric samples (Ø8 $\mathrm{mm} \times 50 \mathrm{~mm}$ ). However, using the SEM technique, precise investigations were conducted at high magnification in the secondary electron mode (SE). As a result, very small voids, just several micrometers in size, were also detected (Figure 11).

\subsection{Mechanical Properties Evaluated by Compression Tests and Hardness}

The compression and hardness tests were selected because they provide the suitable information in the context of the presented structural research.

Uniaxial compression tests were applied in order to investigate the coherence and plasticity of volumetric, massive samples under the acting of high value of stress and plastic deformation. These tests provided information about the coherence and mechanical properties of the products obtained. The yield stress was determined, and the plasticity of the rods was tested. The samples were deformed within a range that significantly exceeded the yield stress. During the tests, the intentional, final value of plastic deformation was relatively high $(\varepsilon=50 \%)$, which resulted in a reduction of the initial height of the sample by half (i.e., from $10.5 \mathrm{~mm}$ to $5.25 \mathrm{~mm}$ ). This value of deformation is unattainable in the case of the tensile tests.

All the samples V1-V4 were selected for the research. For comparison, the material in as-received state was also tested. Based on the results of computer tomography it was assumed, that the samples of V4 variant had the greatest amount of defects (porosity), therefore it was most vulnerable to destruction. Thus, the V4 samples were characterized by the highest risk of cracks and decohesion. In sample V4, the absence of failure and the 
possibility of plastic deformation would be the evidence of high quality of manufactured materials.

The strain-stress curves obtained based on the compression tests are presented in Figure 12. As can be seen, in all the samples V1-V4 the deformation phenomena proceeded properly and similarly. The courses of compression for the samples V1-V4 were analogous to those for the material in the as received state, what is a particularly important and favorable result. All the samples examined reacted to the compressive stress in the same way. For all of them, the stage of elastic deformation was followed by a stage of plastic deformation. The graphs show a gradual strengthening of the materials. During the application of the stress, there were no clear and significant stress fluctuations or jumps. This proves that no significant cracking or fracturing occurred during compression, and that the materials did not separate. Throughout the broad scope of deformation applied, the materials deformed plastically and remained coherent. The course of the compression curves confirms the results of the macroscopic observations that only small, insignificant, local surface cracks and local surface delaminations occurred. This applies to all samples and is a particularly favorable result for the samples after chip consolidation.

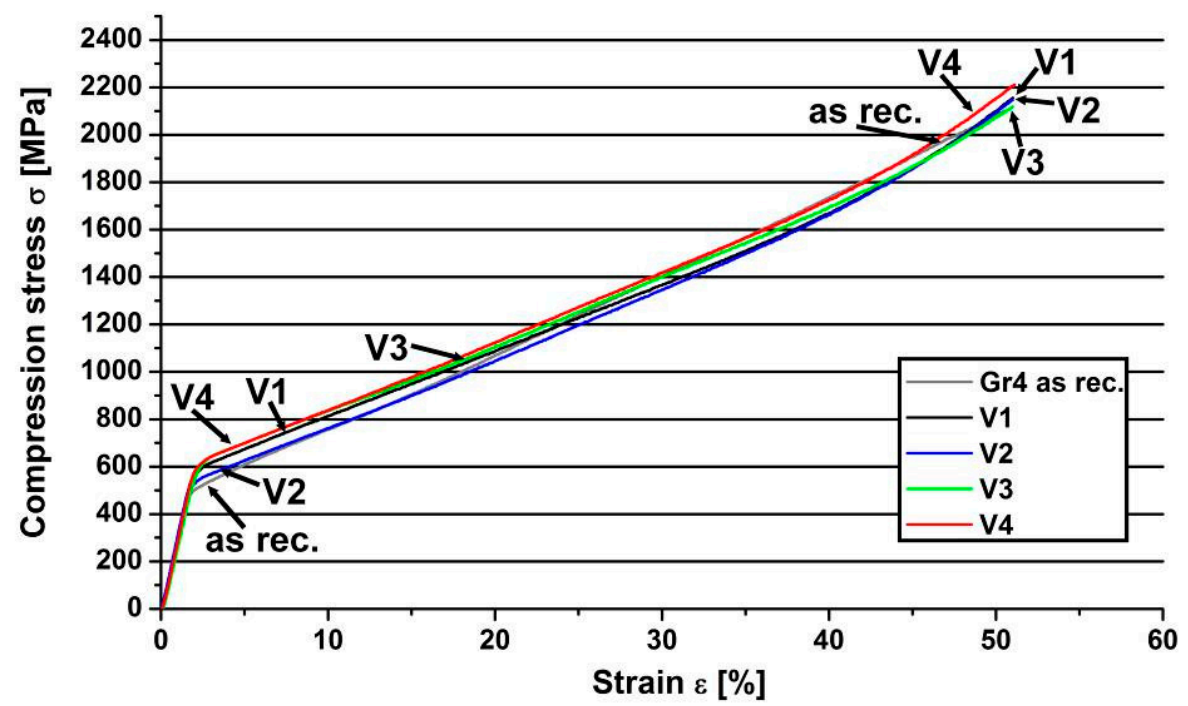

Figure 12. Strain-stress curves obtained from the compression tests.

Based on the strain-stress records, it was possible to determine the yield stress (Table 9). Comparing the values, it was found, that the titanium after chips processing were characterized by higher values of yield stress than the titanium in as-received state. Analyzing the structure and the mechanical results together, an additional strengthening mechanism could be observed. This was strengthening by grain boundaries caused by the grain refinement, because, in the extruded rods, significantly smaller grains were present. This phenomenon was widely discussed in the previous chapters. The results of yield strength obtained for samples after milling are slightly higher than those obtained for samples after turning. However, the differences are insignificant and the results are similar. Hence, no clear influence of the chip geometry on the yield stress was stated. Regardless of the values of the yield stress, the obtained results were within the range typical for titanium Gr4. These results are particularly important and beneficial in the context of titanium obtained by processing chips. 
Table 9. Mechanical properties obtained for as-received $\mathrm{Ti}$ and processed Ti evaluated from the uniaxial compression tests.

\begin{tabular}{ccccccc}
\hline \multicolumn{2}{c}{ Sample Ti Gr4 } & As Received & V1 & V2 & V3 & V4 \\
\hline Yield stress & test No.1 & 493 & 563 & 521 & 589 & 588 \\
\cline { 2 - 7 }$\sigma_{\mathbf{0 . 2}}[\mathrm{MPa}]$ & test No.2 & 490 & 565 & 525 & 594 & 593 \\
\hline
\end{tabular}

It should be emphasized that all the tested samples were characterized by very good plasticity. In each case, the large deformation value $(\varepsilon=50 \%)$ planned was achieved. These results are important and encouraging, especially in the cases of samples V1-V4, which were manufactured from chips, i.e., from a dispersed form. None of the samples was destroyed (defragmented) into separate parts, and so the compressive strength of the materials was not calculated.

The results of the macroscopic observations of the samples after the compression tests are shown in Figure 13. They are consistent with the recorded compression curves. The macroscopic examination proved that all of the samples remained coherent, which is especially important in the cases of samples V1-V4, which were obtained from chips. The samples did not crack into separate parts, nor was any defragmentation observed. In some cases, local, relatively small surface defects were found. However, these were only local delaminations on the circuit of the samples. They resulted from the local porosity and maximum tensile stresses acting on the circumference.
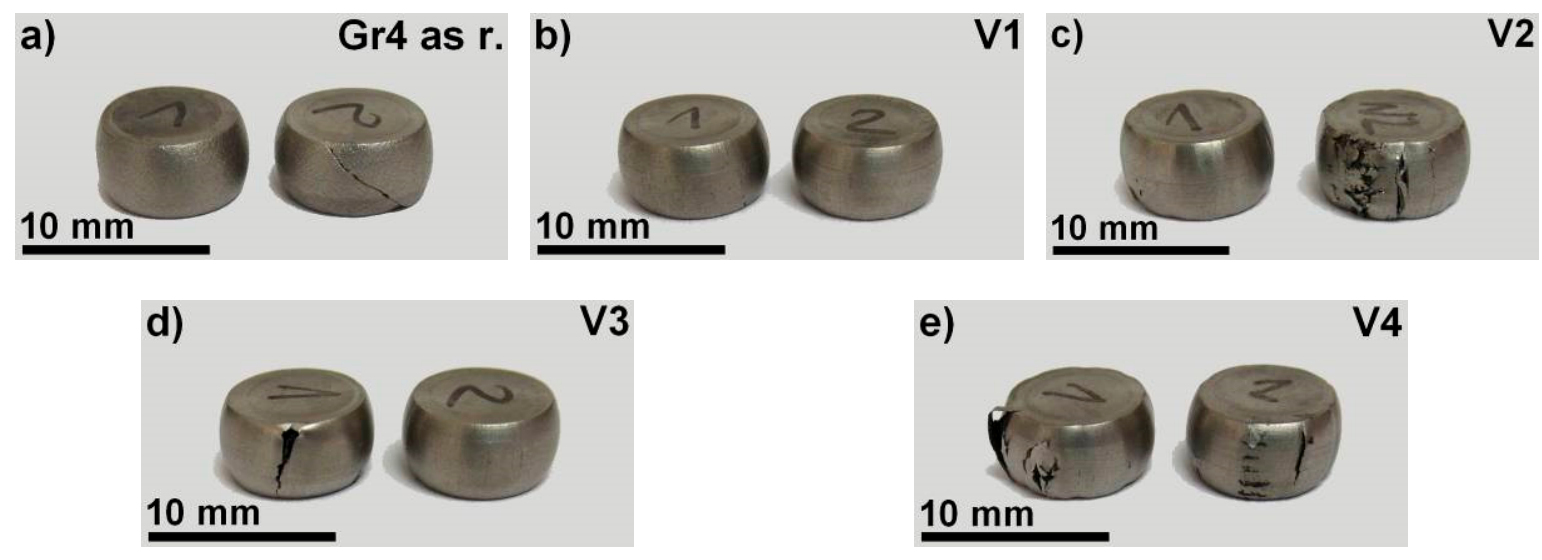

Figure 13. Macroscopic view of the samples after the uniaxial compression tests: (a) Ti Gr4, as received state, (b) variant V1, (c) variant V2, (d) variant V3, (e) variant V4.

The results of compression tests are another evidence of the chips transformation and of the forming of new, high-strength interatomic bonding.

The results of the hardness measurements (HV10) revealed that all of the obtained materials V1-V4 were characterized by the hardness in the range of 196-211 HV10. These values were very close to the hardness of Ti Gr4 in the as received state (190 HV10). This means that hardness of the manufactured rods is proper and typical for the hardness of commercial TiGr4. Therefore, the results of the HV10 measurements are another proof that the structure of the rods obtained is correct. Moreover, in the context of the presented structural research, the measurements of hardness also provided other important information. Namely, the measurements were made under a relatively high load of $10 \mathrm{~kg}(\sim 100 \mathrm{~N})$. Despite this, during the tests, all the samples V1-V4 remained coherent and none of them has been damaged by cracks or decohesion. 


\section{Summary and Conclusions}

In this work, four variants of pure titanium chips were processed in order to consolidate and transform this dispersed form into solid, bulk materials. These four variants were Ti Gr4 chips after: turning (thin, coarse) and after milling (thin, coarse). The applied plastic working technology consisted of preliminary upsetting followed by direct extrusion at an elevated temperature using a rotating die (the $\mathrm{KOBO}$ method). A characteristic feature of the processing applied was that the deformed chips always remained in the solid state. In addition to the above, the following conclusions have been formulated:

1. The technology applied resulted in processing the chips into bulk, volumetric products in the form of rods $\varnothing 8 \mathrm{~mm}$ in diameter and with a length in a range of from 400-600 mm.

2. A dispersed form (chips) was successfully transformed into new, consolidated, solid state structures.

3. The manufactured rods were characterized by structures with a value of porosity between $0.02-0.54 \%$ and a density equal $4.50 \mathrm{~g} / \mathrm{cm}^{3}$.

4. The new structures of the manufactured rods were typical of commercial titanium. In this work, polycrystalline, grained microstructures were obtained, having equiaxial grains with an average size in the range $3-5 \mu \mathrm{m}$.

5. In all the rods, new, monolithic structures without initial chip boundaries were formed, which confirms the presence of new atomic bonds in the materials.

6. Within the compression tests, it was found that the manufactured rods exhibited proper cohesion and were not brittle. The rods were characterized by new interatomic bonds, cohesive forces and plasticity analogous to those of titanium in the as-received state.

Author Contributions: Conceptualization, K.T.; methodology, K.T.; formal analysis, K.T. and H.G.; investigation, K.T. and J.J.; writing_original draft preparation, K.T.; writing—review and editing, K.T.; supervision, K.T.; project administration, K.T.; funding acquisition, K.T. All authors have read and agreed to the published version of the manuscript.

Funding: This research was funded by National Science Center, POLAND (Narodowe Centrum Nauki, POLSKA), grant number UMO-2017/26/D/ST8/00051.

Institutional Review Board Statement: Not applicable.

Informed Consent Statement: Not applicable.

Data Availability Statement: Not applicable.

Conflicts of Interest: The authors declare no conflict of interest.

\section{References}

1. Shamsudin, S.; Lajis, M.A.; Zhong, Z.W. Evolutionary in Solid State Recycling Techniques of Aluminium: A review. Procedia CIRP 2016, 40, 256-261. [CrossRef]

2. Tekkaya, A.E.; Schikorra, M.; Becker, D.; Biermann, D.; Hammer, N.; Pantke, K. Hot profile extrusion of AA-6060 aluminum chips. J. Mater. Process. Technol. 2009, 209, 3343-3350. [CrossRef]

3. Wen, L.; Ji, Z.; Li, X.; Xin, M. Effect of Heat Treatment on Microstructure and Mechanical Properties of ZM6 Alloy Prepared by Solid Recycling Process. J. Mater. Eng. Perform. 2010, 19, 107. [CrossRef]

4. Mal'kov, A.V.; Shevchenko, V.V.; Nizkin, I.D.; Luk'yanova, E.V. Structure and Properties of Hot-Rolled Strips Obtained from Titanium Chips without Chip Remelting. Russ. J. Non Ferrous Met. 2008, 49, 258-260. [CrossRef]

5. Lapovok, R.; Qi, Y.; Ng, H.P.; Maier, V.; Estrin, Y. Multicomponent materials from machining chips compacted by equal-channel angular pressing. J. Mater. Sci. 2014, 49, 1193-1204. [CrossRef]

6. Zhilyaev, A.P.; Gimazov, A.A.; Raab, G.I.; Langdon, T.G. Using high-pressure torsion for the cold-consolidation of copper chips produced by machining. Mater. Sci. Eng. A 2008, 486, 123-126. [CrossRef]

7. Luo, P.; McDonald, D.T.; Palanisamy, S.; Dargusch, M.S.; Xia, K. Ultrafine-grained pure Ti recycled by equal channel angular pressing with high strength and good ductility. J. Mater. Process. Technol. 2013, 213, 469-476. [CrossRef]

8. Lui, E.W.; Palanisamy, S.; Dargusch, M.S.; Xia, K. Effects of chip conditions on the solid state recycling of Ti-6Al-4V machining chips. J. Mater. Process. Technol. 2016, 238, 297-304. [CrossRef] 
9. Shi, Q.; Tse, Y.Y.; Higginson, R.L. Effects of processing parameters on relative density, microhardness and microstructure of recycled Ti-6Al-4V from machining chips produced by equal channel angular pressing. Mater. Sci. Eng. A 2016, 651, 248-258. [CrossRef]

10. Topolski, K.; Bochniak, W.; Łagoda, M.; Ostachowski, P.; Garbacz, H. Structure and properties of titanium produced by a new method of chip recycling. J. Mater. Process. Technol. 2017, 248, 80-91. [CrossRef]

11. Korbel, A.; Bochniak, W.; Śliwa, R.; Ostachowski, P.; Łagoda, M.; Kusion, Z.; Trzebuniak, B. Low-temperature consolidation of machining chips from hardly-deformable aluminum alloys. Met. Form. 2016, 27, 133-152.

12. Baffari, D.; Buffa, G.; Campanella, D.; Fratini, L.; Reynolds, A.P. Process mechanics in Friction Stir Extrusion of magnesium alloys chips through experiments and numerical simulation. J. Manuf. Process. 2017, 29, 41-49. [CrossRef]

13. Tang, W.; Reynolds, A.P. Production of wire via friction extrusion of aluminum alloy machining chips. J. Mater. Process. Technol. 2010, 210, 2231-2237. [CrossRef]

14. Gronostajski, J.; Matuszak, A. The recycling of metals by plastic deformation: An example of recycling of aluminium and its alloys chips. J. Mater. Process. Technol. 1999, 92-93, 35-41. [CrossRef]

15. Wan, B.; Chen, W.; Lu, T.; Liu, F.; Jiang, Z.; Mao, M. Review of solid state recycling of aluminum chips. Resour. Conserv. Recycl. 2017, 125, 37-47. [CrossRef]

16. Hu, M.L.; Ji, Z.S.; Chen, X.Y.; Wang, Q.D.; Ding, W.J. Solid-state recycling of AZ91D magnesium alloy chips. Trans. Nonferrous Met. Soc. China 2012, 22, 68-73. [CrossRef]

17. Peng, T.; Wang, Q.D.; Han, Y.K.; Zheng, J.; Guo, W. Consolidation behavior of Mg-10Gd-2Y-0.5Zr chips during solid-state recycling. J. Alloys Compd. 2010, 503, 253-259. [CrossRef]

18. Qi, Y.; Timokhina, I.B.; Shekhter, A.; Sharp, K.; Lapovok, R. Optimization of upcycling of Ti-6Al-4V swarf. J. Mater. Process. Technol. 2018, 255, 853-864. [CrossRef]

19. Wejrzanowski, T.; Spychalski, W.L.; Rożniatowski, K.; Kurzydłowski, K.J. Image based analysis of complex microstructures of engineering materials. Int. J. Appl. Math. Comput. Sci. 2008, 18, 33-39. [CrossRef]

20. Nouari, M.; Makich, H. On the Physics of Machining Titanium Alloys: Interactions between Cutting Parameters, Microstructure and Tool Wear. Metals 2014, 4, 335-358. [CrossRef]

21. Shunmugavel, M.; Goldberg, M.; Polishetty, A.; Nomani, J.; Sun, S.; Littlefair, G. Chip formation characteristics of selective laser melted Ti-6Al-4V. Aust. J. Mech. Eng. 2019, 17, 109-126. [CrossRef] 